Revista lus et Praxis, Año 20, № 2, 2014, pp. 375 - 414

ISSN 0717 - 2877

Universidad de Talca - Facultad de Ciencias Jurídicas y Sociales

"Fragmentos de un Imaginario Judicial de la Sana Crítica"

Rodrigo Coloma Correa

Claudio Agüero San Juan

Trabajo recibido el 25 de marzo y aprobado el 12 de mayo de 2014

\title{
Fragmentos de un Imaginario Judicial de la Sana Crítica*
}

Fragments of a Judicial Imaginary about Sound Criticism

\author{
Rodrigo Coloma Correa** \\ Claudio Agüero San Juan***
}

\begin{abstract}
Resumen
Esta es una investigación sobre el imaginario judicial de la Sana Crítica. El enfoque es cualitativo y las conclusiones no admiten proyección estadística de lo que hacen y piensan los jueces chilenos. El interés radica en que presenta construcciones mentales compartidas por algunos actores relevantes, las que no aparecen como preferencias puramente individuales sino como productos de la interacción social (no puramente casual). La metodología aplicada es propia de problemáticas en las que existe escaso desarrollo teórico, focalizándose en la auto-comprensión de un grupo de jueces que diariamente deben enfrentarse a la exigencia legal de valorar la prueba. El análisis considera información producida a través de entrevistas semi-estructuradas aplicadas por separado a seis jueces. Las respuestas fueron grabadas, transcritas y analizadas con técnicas estandarizadas de análisis de discurso. Las conclusiones son: i) existe un imaginario judicial de la Sana Crítica que aspira a una racionalidad objetiva; ii) el imaginario judicial de la Sana Crítica está construido a partir de la experiencia biográfica en razón de la carencia de estructuras conceptuales validadas por la dogmática y/o precedentes judiciales.
\end{abstract}

\section{ABSTRACT}

The research focuses on the judicial imaginary about Sound Criticism. It adopts a qualitative approach and its conclusions do not support statistical projections on what Chilean judges do and think. The relevance of the research lies on how it shows that mental constructs are shared by some stakeholders and, therefore, they do not appear as purely individual preferences but as the products of social interaction (not purely coincidental). The methodology chosen is consistent with an issue in which there is little theoretical development, focusing on the self-understanding of a group of judges who daily have to face the legal duty to examine the evidence. The analysis considers information gathered through semi-structured interviews, individually applied to six judges. Responses were recorded, transcribed and reviewed with standardized discourse analysis techniques. The conclusions of the research are: i) there is a judicial imaginary about Sound

\footnotetext{
* Este trabajo corresponde a resultados del Proyecto financiado por el Fondo Nacional de Desarrollo Científico y Tecnológico, FONDECYT N 1110409 "La construcción de lo probado en los procesos judiciales. Vaivenes entre la ciencia, la lógica, el sentido común y la íntima convicción del juzgador".

** Profesor de la Universidad Alberto Hurtado (Santiago, Chile). Doctor en Derecho. Correo electrónico: rcoloma@uahurtado.cl.

** Profesor de la Universidad Alberto Hurtado (Santiago, Chile). Doctor en Ciencias Humanas. Correo electrónico: aguero.claudio@gmail.com.
} 
Criticism that aspires to objective rationality; ii ) judicial imaginary about Sound Criticism is construed upon the biographical experience of each judge, due to the lack of conceptual structures validated by legal theory and/or judicial precedents.

\section{PALABRAs CLAVE}

Imaginarios, Sana crítica, Jueces, Análisis del discurso, Etnografía judicial

KEYWORDS

Imaginaries, Sound criticism, Judges, Discourse analysis, Judicial ethnography

"Los tribunales no tratan de averiguar la verdad acerca de ciertos eventos interesantes sino solo encontrar -mediante un procedimiento legalmente prescrito- los hechos relevantes para un cierto problema jurídico [...] Por lo tanto, en sentido estricto, no hay contradicción posible entre las conclusiones acerca de los hechos de un tribunal de justicia y las de experiencia científica y de la experiencia cotidiana." Michael Polanyi. Personal knowledges.

\section{Introducción ${ }^{1}$}

Esta es una investigación empírica, cualitativa y exploratoria acerca de lo que los jueces piensan sobre la Sana Crítica, en adelante SC. Intentamos con ella cubrir un pequeño fragmento de la extensa brecha de ignorancia que existe respecto a cómo los jueces conciben y afrontan su trabajo. Para tal efecto, la aproximación de la investigación es constructivista y descriptiva. El constructivismo se expresa en el intento por reconstruir el punto de vista de los jueces entrevistados sin forzarlo a que calce con teorías definidas a priori. La investigación es descriptiva porque su objetivo principal es prestar una modesta contribución a la elaboración de una etnografía del trabajo judicial en Chile, visibilizando esa experiencia profesional como un tópico importante en la respuesta a la pregunta sobre la efectividad del Rule of Law.

La primera sección del texto enfrenta la red de conceptos implicada en la investigación. La segunda sección expone la metodología usada. Las secciones tercera y cuarta exponen y analizan fragmentos ilustrativos del discurso de los jueces y, finalmente, la quinta sección presenta conclusiones que son una síntesis de nuestros juicios sobre lo que ha sido comunicado en el discurso de los jueces entrevistados.

\footnotetext{
${ }^{1}$ Los resultados que aquí se presentan fueron posibles por la generosa colaboración de los seis jueces entrevistados, como también de otros dos que se sometieron a entrevistas piloto a fin de perfeccionar el instrumento aplicado. A todos ellos agradecemos su valiosa y desinteresada contribución. Agradecemos también a Mauricio Pino Yankovic por sus agudas observaciones en el diseño del instrumento empleado en las entrevistas, por la aplicación rigurosa de las entrevistas y por el completo informe de las tareas realizadas. Finalmente, reconocemos la valiosa ayuda de Victoria Martínez Placencia en la tarea de ajustar el texto a las exigencias formales de la revista. El texto que aquí se publica fue discutido en el Seminario 3 de la Facultad de Derecho de la Universidad Alberto Hurtado, agradeciendo los autores los comentarios recibidos de parte de los distintos intervinientes.
} 


\section{Marco conceptual}

\subsection{Las incertidumbres de la SC}

Las reformas procesales que se han implementado en nuestro país en el transcurso de las dos últimas décadas han optado por la SC, en cuanto modelo de valoración de la prueba ${ }^{2}$. Aunque ésta no ha sido la modificación más vistosa resulta digna de considerar pues prescinde de una reglamentación detallada de la actividad del juez, no obstante esperarse que traiga aparejadas importantes implicaciones prácticas. La dificultad de los juristas y de los tribunales superiores para dotar de contenido al modelo (abierto) de valoración de la prueba conforme a la SC, ha llevado a que los jueces dispongan de amplios márgenes de actuación, y a la ausencia de un modo de pensar compartido. Se sospecha que entre los jueces existe cierto grado de duda sobre qué significa valorar la prueba con libertad; qué significan los límites a esa libertad y sobre qué estándares de desempeño argumental les son exigibles para que se entienda que respetan las disposiciones existentes.

El legislador ha entendido que existe una relación muy estrecha entre valorar la prueba en conformidad a la $\mathrm{SC}^{3}$ y el someterse a los principios de la lógica, a las máximas de la experiencia y a los conocimientos científicamente afianzados ${ }^{4}$. Aun cuando la utilización de dichas categorías dota a la SC de un mayor grado de precisión, el impacto que aquello representa no sería lo suficientemente alto como para resolver el problema de cómo debe valorarse la prueba disponible en un juicio ${ }^{5}$. En pocas palabras, que el legislador diga que los jueces deben someterse a los principios de la lógica, a las máximas de

\footnotetext{
${ }^{2}$ En el proyecto de modificación al proceso civil -en actual tramitación en el congreso- la opción es mucho menos radical que en procesos ya modificados.

3 Respecto a las discrepancias acerca de lo que se habría pretendido al introducir la noción de sana crítica en la legislación española y en la chilena, ver BeNFELD (2013), pp. 571 y ss.

${ }^{4}$ Así, por ejemplo, en el artículo 456 del Código del Trabajo (que es idéntico al de otros cuerpos legislativos) se dice que "El tribunal apreciará la prueba conforme a las reglas de la sana crítica. Al hacerlo, el tribunal deberá expresar las razones jurídicas y las simplemente lógicas, científicas, técnicas de experiencia, en cuya virtud les asigne valor o las desestime". Los jueces y abogados, en general, han asimilado esta relación ya que, por ejemplo, en el Código Procesal Penal no se habla de SC, pero se suele entender que aquél es el modelo que opera desde el momento en que en dicho texto normativo se alude a las limitaciones propias de los principios de la lógica, máximas de la experiencia y conocimientos científicamente afianzados.

${ }^{5}$ Sobre la sana crítica y desde una perspectiva de la dogmática procesal, puede verse, entre otros, Nieva (2010), especialmente pp. 88 y ss.; sobre principios de la lógica Laso (2009), pp. 143-164; sobre máximas de la experiencia TARUFFO (2001), pp. 665-695 y sobre conocimientos científicamente afianzados HaACK (2001), pp. 217-245; Huber (1993), pp. 1 y ss. La literatura disponible, por cierto, es mucho más amplia.
} 
la experiencia y a los conocimientos científicamente afianzados ${ }^{6}$ deja abierto un abanico amplio de posibilidades en el contexto de la determinación de lo que debe darse por probado en un juicio (aunque éste sea bastante más reducido que el propio de un escenario en que se dijese a los jueces que den por probado lo que ellos estimen que debe darse por probado). De esta manera, las expectativas que tienen los juristas sobre la SC suelen verse frustradas ante la constatación de que no estamos siendo capaces de ir más allá de lo que nos ofrece ese modo de pensar que llamamos cultura, a los efectos de domesticar el pasado que se discute en los juicios ${ }^{7}$.

La desregulación de la actividad de los jueces tensiona las expectativas que los abogados y los ciudadanos tienen sobre la administración de justicia cuando ellos actúan como partes interesadas en un proceso. La dinámica del proceso genera expectativas antagónicas y no colaborativas entre las partes, porque cada una de ellas siempre aspira a liberarse de cargas y, a contrario, espera que le sean impuestas a su contraparte. Como mecanismo de legitimación de la tarea del adjudicador, los abogados y los ciudadanos que intervienen en un proceso esperan de éste una decisión transparente en términos de las razones que la sustentan, rápida en relación al tiempo que toma la resolución y clara en relación a cuál de las pretensiones resulta satisfecha. La carga de justificación de la decisión del juez que se compromete a ceñirse a las fuentes formales del derecho y a los medios de prueba es clave para reducir los riesgos de desviación. Dejando de lado la justificación de la aplicación de ciertas fuentes formales, la justificación de los hechos relevantes se traduce en una representación del pasado que exige enfrentar la pregunta: ¿Qué es una (masa de) evidencia suficiente para considerar un cierto pasado? De acuerdo al modelo de la SC el derecho guarda silencio y reenvía la pregunta a la comunidad, ya que es el sistema de producción de conocimiento vigente en ella lo que determinará

\footnotetext{
${ }^{6}$ En un artículo que se encuentra actualmente en prensa -"Lógica, Ciencia y Experiencia en la Valoración de la Prueba" - proponemos el significado que debiera atribuirse a los principios de la lógica, máximas de la experiencia y conocimientos científicamente afianzados. En cuanto a los primeros, enfatizamos su función lingüístico-interpretativa que nos protege ante el sentido y el absurdo; en el caso de los otros dos restantes, enfatizamos su función epistémico-cultural, diferenciándose entre ellos por el tipo de comunidad que los genera, por su nivel de legitimación y por sus formas más o menos sofisticadas de producción.

7 El problema que a ello va aparejado es que en otros ámbitos de producción del conocimiento la definitividad de los hechos que se dan por probados no resulta tan radical como en el contexto de los procesos judiciales. Como se sabe, en estos últimos son escasas las posibilidades de hacerse cargo de información relevante que se produce con posterioridad a la decisión y el tiempo en que ésta debe ser tomada no permite dejar pendientes aquellos casos que aparecen como borrosos.
} 
qué es una 'evidencia' y qué cuenta como 'evidencia suficiente' para dar por probado que algo ha pasado ${ }^{8}$.

\subsection{Los imaginarios y la configuración de las prácticas sociales}

Lo que Ilamamos realidad social es una superposición de construcciones mentales colectivas basadas en la experiencia social de diferentes grupos que operan en variados contextos. En vista de ello, su identidad es específica aunque algunos elementos podrían ser compartidos entre grupos de individuos e incluso, por distintas culturas.

En esta investigación usamos la expresión 'imaginario' para aludir a lo que desde otras perspectivas podría entenderse como: 'creencias'; 'percepciones', 'cultura jurídica' o 'ideología'. Hemos preferido usar la voz 'imaginario' por sobre las otras ya que tal expresión comunica de forma simultánea dos ideas importantes: la construcción social de una imagen sobre un fenómeno que puede no coincidir exactamente con la realidad y la guía de conductas individuales por medio de esa construcción social ${ }^{9}$. Un imaginario, entonces, es un esquema construido en la interacción social, que permite a los sujetos percibir algo como real, explicarlo y orientar su conducta de acuerdo a lo que en el sistema social se considera como real ${ }^{10}$. Así, las construcciones mentales que aquí llamamos imaginarios $^{11}$ dependen de las experiencias vividas por las personas o por las agrupaciones de individuos ${ }^{12}$.

En muchos ámbitos de nuestra vida el contar con un imaginario nos permite resolver una serie de problemas donde los expertos carecen de algoritmos para la solución de los problemas que se nos plantean. Por una parte, el imaginario contribuye a enfrentar de manera pronta las decisiones de relevancia de la información que se nos pide evaluar y nos ayuda también a mantener en un

${ }^{8}$ Coloma (2012), pp. 753-781.

${ }^{9}$ Castoriadis (2007), p. 191.

10 JODELET (1986), pp. 469-494.

11 Es interesante considerar que en el avance de la $23^{\mathrm{a}}$ edición del Diccionario de la Lengua Española de la Real Academia Española, se hace una serie de cambios respecto de la versión anterior. Así, en esta ocasión aparecen los siguientes nuevos significados de la palabra "imaginario": "3. m. Imagen que un grupo social, un país o una época tienen de sí mismos o de alguno de sus rasgos esenciales. 4. m. Repertorio de elementos simbólicos y conceptuales de un autor, una escuela o una tradición. 5. m. Psicol. Imagen simbólica a partir de la que se desarrolla una representación mental." Ver http://lema.rae.es/drae/?val=imaginario.

${ }^{12}$ La idea de imaginario da cuenta indirectamente del carácter complejo que se da en el acto de formación del conocimiento. Con ello la corporeidad del sujeto (social) que construye el conocimiento no queda invisibilizada en una concepción ingenua que postula que lo que se conoce es "lo que está ahí afuera", con independencia del sujeto cognoscente. Al respecto puede verse la idea de "enacción" que es defendida por Francisco Varela. Varela et al. (2011), pp. 174 y ss. 
nivel soportable la disonancia cognoscitiva entre nuestras creencias y nuestras acciones. Compartir un imaginario permite reconocer que lo que cada uno de los miembros de la comunidad hace es parte de lo colectivo, y reducir los niveles de incertidumbre frente a fenómenos inexplicables.

Si los imaginarios construyen las prácticas sociales y, al mismo tiempo, esas prácticas modifican lo que las personas piensan que es posible, deseable, correcto o prohibido, podemos Ilamar 'imaginarios legales' al repertorio de imaginarios que fijan el conjunto de cualidades que se espera posean tanto los miembros de la comunidad jurídica como las instituciones creadas por el derecho. Estos imaginarios se reflejan, por ejemplo, en la forma en que las personas comunes ven a los abogados; en las expectativas que otros profesionales tienen de los abogados; en las cualidades que un estudiante de derecho atribuye a la figura del profesor universitario o en la imagen que tienen los abogados litigantes de los ministros del Tribunal que resolverá su caso. Asimismo, los imaginarios legales también condicionan las expectativas de los ciudadanos (y de los mismos abogados) sobre el proceso legislativo, la regulación de los contratos, el proceso penal, la justicia de familia o la tramitación de un amparo ante el Consejo para la Transparencia. La colección de imaginarios legales es entonces un conjunto dinámico y en tensión que no supone coherencia, completitud ni fidelidad con la realidad social.

\subsection{La función de los imaginarios en la configuración de las prácticas judiciales}

El acceso exclusivo a la tarea de adjudicación que tienen los jueces permite privilegiar 'su imaginario' por sobre otros imaginarios legales, tratándose de la práctica de administrar Justicia. A fin de cuentas, pasa a ser la única construcción mental completamente informada para responder a la pregunta ¿qué se hace para resolver un caso que ingresa al sistema judicial? Llamaremos 'imaginarios judiciales' a un subconjunto de los imaginarios legales vinculados a cómo los jueces comprenden las reglas procesales, el trabajo de los abogados y las expectativas de los ciudadanos respecto de su trabajo. En un sentido más restringido, la expresión 'imaginario judicial' la usaremos en lo que sigue para referirnos al imaginario que se devela a partir del discurso de los jueces sobre un asunto específico: el modelo de SC para la valoración de la prueba.

\subsection{Lo que ofrece el análisis del discurso para el conocimiento de los imaginarios}

La perspectiva del análisis del discurso presenta algunas ventajas por sobre un acercamiento teórico, si de lo que se trata es de develar cuáles son las prácticas judiciales. La primera, es ofrecer una comprensión más completa al 
incluir la perspectiva de un grupo de personas. La segunda, es proporcionar información sobre cómo el imaginario, en tanto idea, produce efectos en las conductas de los miembros de un grupo. La tercera, es sugerir modos efectivos para que el sistema de justicia reconozca las necesidades que los jueces tienen como agentes del proceso judicial. Un beneficio adicional que provee estudiar el imaginario judicial de la SC es contar con un punto de partida para conocer en qué medida éste concuerda con los imaginarios que otros grupos relevantes de la comunidad jurídica (fiscales, defensores, querellantes, académicos) tienen sobre aquélla. Así, éste es solo uno de los pasos requeridos para estudiar cuánto consenso existe sobre el significado de la SC en la comunidad jurídica chilena.

En esta investigación la entrevista desempeña un papel central para comprender el imaginario estudiado. A diferencia de otras investigaciones, en donde ésta se combina con otros instrumentos como el cuestionario o el focus group, la entrevista no ha sido concebida como un acto de observación de la realidad social, sino como una instancia de interacción a través de la cual los investigadores acceden a cómo el entrevistado comprende su mundo profesional. Las entrevistas se realizaron pensando en que contribuirían a comprender al entrevistado, antes que a las variables en que éste se focaliza. Por ello, el análisis de los datos no fue fragmentado en variables sino que de forma tópica, intentando construir un relato sobre el imaginario compartido por los jueces entrevistados. En otras palabras, el objetivo no es entender las relaciones entre las variables, sino comprender cómo las experiencias vividas modulan la forma de entender el funcionamiento del ordenamiento jurídico. En consecuencia, el punto de partida es el entrevistado y no la variable.

El análisis del discurso considera que los textos de las entrevistas son un soporte en el que se expresan significados resultantes de la interacción propia de la conversación. Esos significados presentan los siguientes aspectos: tienen un valor simbólico -aunque éste no siempre es manifiesto-; no son unidireccionales, ya que el significado pretendido por el autor puede no coincidir con el significado percibido por el lector del mismo; e incluso más, el significado del discurso puede ser diverso para lectores diferentes ${ }^{13}$. Consecuentemente, la idea central del análisis del discurso es que el texto debe entenderse como el producto de un diálogo y no como un conjunto de datos que son solo procesados e interpretados.

13 Ruiz (1996), p. 51. 


\section{Metodología}

Esta es una investigación cualitativa y por ello no busca arribar a conclusiones generalizables en un sentido estadístico ${ }^{14}$. De lo que se trata es de generar teoría y obtener enunciados generalizables en un sentido analítico ${ }^{15}$. La cuestión metodológica no es entonces cómo construir una muestra probabilística que sea representativa de una población de individuos, sino que cómo fundar (en la información recopilada) fragmentos de una teoría que sea transferible a otros casos similares ${ }^{16}$.

Es claro que la metodología elegida no cumple con los criterios de validación de los estudios cuantitativos ${ }^{17}$. Sin embargo, ello no permite cuestionar la cientificidad de sus resultados puesto que la metodología cualitativa no compite con la cuantitativa ${ }^{18}$. La metodología cualitativa es la única forma de estudiar problemas de investigación en contextos donde las teorías son inadecuadas o simplemente inexistentes.

Los datos producidos permiten analizar cómo un grupo de jueces imaginan que la comunidad jurídica y la sociedad observa su trabajo y, al mismo tiempo, cómo ellos se observan a sí mismos. Siguiendo lo planteado por Ruiz ${ }^{19}$, tuvimos en cuenta los dos principales rasgos definitorios de las investigaciones de este tipo. Primero, se debe contar con una visión global del fenómeno a estudiar, donde cada objeto de investigación debe ser entendido como un texto enmarcado en un contexto. Segundo, no se debe perder contacto con la realidad inmediata de las condiciones de trabajo de los entrevistados: así, la generación de las categorías intenta mantenerse próxima al discurso analizado.

El instrumento aplicado cuenta con cinco ejes: el primero refiere a la experiencia, contexto y formación como juez; el segundo, a la SC como mecanismo de valoración de la prueba; el tercero, a los conocimientos científicamente afianzados y, en especial, al caso de la prueba pericial; el cuarto, a las máximas de la experiencia; y el quinto, a los principios de la lógica. Al final se da la posibilidad de referir a cualquier punto no tratado o bien se invita a volver sobre alguno ya referido y en que se quiera profundizar.

Antes de exponer en detalle el proceso de producción de la información es necesario dar cuenta de aspectos (decisiones) teórico-metodológicos de la investigación que condicionan la interpretación de los resultados obtenidos: i) el enfoque que inspira el diseño de la entrevista; ii) el valor de la relación entre

14 Dachler (1997), pp. 709-724; MejÍA (2004), pp. 277-299.

15 Chetty (1996), p. 80; YIN (1989), pp. 127 y ss.

16 MaXwell (1998), p. 75.

17 StOeker (1991), pp. 90.

18 Carrizo et al. (2004), p. 11.

19 Ruiz (1996), p. 51. 
el entrevistado y el investigador; iii) el tipo de comunicación que hace posible la aplicación de una entrevista; iv) el valor a asignar a las estrategias discursivas; v) la tensión existente entre la comprensión conceptual y las vivencias de los jueces y, vi) el sistema de selección de los participantes.

\subsection{Una investigación exploratoria y parcialmente émica}

La investigación es exploratoria porque el discurso de los jueces chilenos es un objeto poco estudiado ${ }^{20}$. En este sentido, uno de los resultados de la investigación es delinear con mayor precisión el objeto investigado y la metodología de análisis que resulta idónea para construir una etnografía de la comunidad jurídica chilena.

La carencia de estudios empíricos profundos sobre los abogados y jueces chilenos impidió recurrir a investigaciones precedentes sobre la dinámica de la comunidad jurídica chilena. En este sentido, la investigación usa un enfoque parcialmente émico (emic) ${ }^{21}$, es decir, desde adentro de la comunidad jurídica, porque la investigación se diseñó a partir de saberes idiosincrásicos sobre los jueces que los investigadores tienen al ser ellos mismos abogados. El enfoque émico es solo parcial porque los investigadores no han trabajado como jueces.

\subsection{El valor de la relación entre el entrevistado y el investigador}

La entrevista fue diseñada cuidando de no resquebrajar la confianza que los jueces depositaron en la investigación. En este sentido se tomaron varias decisiones como la de no repreguntar de un modo incisivo y, a la vez, promover una conversación en lugar de un interrogatorio. Aun cuando aquello podía incidir en la falta de profundización de algunos puntos interesantes, nos pareció valioso asumir esta perspectiva ya que lo que se dice de manera espontánea en un ambiente de confianza debiera reflejar mejor el imaginario de los jueces que lo que ocurriría si se optase por la vía confrontacional.

La entrevista no fue aplicada por los autores de este texto sino por un psicólogo, quien ya había realizado una tarea similar en otra investigación ${ }^{22}$. La entre-

\footnotetext{
${ }^{20}$ Coloma et al. (2009), pp. 3-56.

${ }^{21}$ Los conceptos de émico (emic) y ético (etic) fueron usados por primera vez por Pike. Luego los adoptó Harris y desde mediados de la década de los setenta del siglo pasado adquirieron carta de ciudadanía en los estudios sociales. Pike (1967); Harris (1976); Harris (1980); Headland et al. (1990); KitAYAMA Y COHEN (2007), p. 67.

${ }^{22}$ Según se anticipó en una nota precedente se trata de Mauricio Pino Yankovic, quien luego de realizar tareas docentes en la PUCV, se encuentra actualmente cursando un programa de doctorado en la Universidad de Illinois Urbana-Champaign, Estados Unidos. La investigación anterior en la que él mismo participó fue Coloma et al. (2009).
} 
vista pudo adquirir, así, una dinámica propia no de quien se siente interpelado, sino de quien está dando cuenta de sus vivencias y de la red conceptual que le permite enfrentar diariamente la tarea judicial ${ }^{23}$. El efecto que esto provoca es evidente en cuanto a que los entrevistados fueron mucho más propensos al uso de un lenguaje coloquial desde el cual resulta difícil evadirse de las dificultades que representa la función de adjudicación. En otras palabras, que la entrevista fuese realizada por un psicólogo invitaba a los jueces a no sentirse controlados por un miembro de su misma comunidad disciplinaria, que como tal podía situarse en una posición simétrica a la de ellos y eventualmente objetar lo que se decía. Al mismo tiempo, la participación del psicólogo garantizaba reducir las implicaturas y presuposiciones al mínimo, ya que el entrevistado no podía suponer razonablemente que su interlocutor conocía el trabajo judicial y, en consecuencia, requería ser especialmente explícito y transparente. Sin perjuicio de lo señalado, en el análisis de las entrevistas los investigadores usaron las implicaturas y las presuposiciones para representar los tópicos y la estructura informativa de la entrevista, ya que las nociones de presuposición e implicatura permiten entender que es necesario contextualizar el uso de la lengua y tomar conciencia del valor socio-cultural de las palabras ${ }^{24}$.

\subsection{Las entrevistas como práctica discursiva}

Una entrevista es una instancia de comunicación verbal que no es espontánea y en donde los roles de los participantes (entrevistador y entrevistado) son fijos. Estas cualidades distinguen a la entrevista de otros formatos de comunicación verbal como el diálogo, la conversación y la discusión. En todos estos formatos de comunicación sus participantes tienen la obligación de interactuar con los otros, de un modo que no es solo verbal sino que involucra elementos no verbales (gestos, posturas, sonrisas), elementos paraverbales (volumen, intensidad, pausas, silencios) y elementos contextuales (el tipo de situación comunicativa y variables socioculturales como la edad, la profesión de los participantes).

La entrevista que hemos realizado es una instancia de comunicación que es ajena al trabajo judicial cotidiano ${ }^{25}$. En razón de la discontinuidad entre las entrevistas y las rutinas de producción de textos de los jueces, ellas fueron

\footnotetext{
${ }^{23}$ Sin perjuicio de lo señalado, uno de los entrevistados mencionó en varias oportunidades el nombre del primero de los autores, con lo que el entrevistador era entendido como un intermediario entre el investigador y el entrevistado.

${ }^{24}$ No profundizaremos en cuestiones metodológicas de análisis de discurso, ya que entendemos que nuestro lector ideal o modelo (no empírico) estaría interesado más en cuestiones normativas que lingüísticas o discursivas.

25 Pérez (2008), pp. 95-110.
} 
diseñadas y analizadas a partir de una versión simplificada del modelo de investigación del análisis crítico del discurso de Norman Fairclough ${ }^{26}$. Este modelo conecta la descripción textual de la transcripción del intercambio oral y el análisis del discurso con una red más amplia de prácticas socioculturales a través de la noción de práctica discursiva. Una práctica discursiva es, según Fairclough, una práctica social que se manifiesta en un texto oral o escrito y que posibilita un intercambio comunicativo en un ámbito público o privado. Ejemplos de estas prácticas son las cartas, los emails, las sentencias judiciales, los discursos políticos, las fotografías y las noticias de los periódicos, etcétera. Así, la entrevista puede definirse como una práctica discursiva porque ella se manifiesta en un texto que posibilita una interacción en una esfera privada ${ }^{27}$.

El análisis crítico de la entrevista en tanto práctica discursiva exige iniciar el análisis en la descripción de la transcripción de la entrevista para continuar en la interpretación de las prácticas sociales sobre las cuales progresa el diálogo. Para realizar el análisis es necesario considerar que la entrevista pertenece a un "género" o tipo de texto ${ }^{28}$. Tanto el entrevistador como el entrevistado saben, antes de iniciar el diálogo, que la entrevista es una variedad de discurso que está regulada por ciertas reglas, aunque muchas de ellas no sean ni siquiera explicitadas; como la alternancia de turnos de habla, es decir, la sucesión más o menos coordinada de las intervenciones de cada uno de los participantes. En la entrevista la distribución de los turnos es predefinida por el género: quien describe una entrevista, sabe que uno de sus rasgos más distintivos es que uno de los participantes es quien realiza las preguntas mientras que el otro es quien las responde y que esta dinámica se repite no siempre de forma rígida, sino que suelen ocurrir interrupciones, solapamientos y el entrevistado puede hacer preguntas aclaratorias al entrevistador ${ }^{29}$.

\subsection{El valor de las estrategias discursivas}

El texto que produce la entrevista es el resultado de los movimientos de todos sus intervinientes, y por ello el significado que el entrevistador comunica es el resultado de una negociación lingüística con el entrevistador ${ }^{30}$. El texto

\footnotetext{
${ }^{26}$ FairClOugh (1995), p. 9. No es posible desconocer que la posición de Fairclough tiene un componente crítico de los discursos hegemónicos e institucionalizados. La elección de Fairclough se justifica entonces porque pensamos que los imaginarios judiciales debiesen usarse, junto a otras variables, para rediseñar el sistema de administración de justicia.

27 Calsamigla y Tusón (1999).

28 FAIRCLOUGH (1995), p. 10.

${ }^{29}$ Cortés y Camacho (1998).

30 BaKhtín (1981).
} 
tiene entonces una propiedad importante: la textura. La textura de un texto es el conjunto de factores que modula lo que las palabras comunican más allá de su significado literal ${ }^{31}$. La textura posibilita interpretar que la entrevista es, al mismo tiempo, una conversación (no espontánea) y un relato (story) sobre la interacción ocurrida entre el entrevistador y el entrevistado. Así, la textura permite entender que la entrevista es más que un listado de preguntas y respuestas y permite leer la entrevista como el resultado de un proceso cooperativo ${ }^{32}$ en donde los intervinientes se han coordinado y han comprometido su actuar discursivo según ciertos acuerdos comunicativos. Estos acuerdos, no siempre explícitos, son la expresión de las competencias comunicativas de los intervinientes y condicionan la interpretación del texto. Ya que el entrevistador y el entrevistado saben que sus intervenciones pueden ser interpretadas de formas diversas y que el sentido de lo que han dicho depende de una decisión del receptor, la interpretación del diálogo resultante debe tener conciencia de que él es fruto de un esfuerzo mutuo por fijar el valor pragmático de lo que se ha dicho.

Al responder a las preguntas el entrevistado siempre deja pistas (especialmente lingüísticas) que tienen por función ayudar al receptor en la búsqueda del significado que el entrevistado quiere que el oyente destaque. Estas pistas son llamadas estrategias comunicativas, discursivas o retóricas. Aquí usaremos la expresión "estrategias discursivas" siguiendo a Gumperz ${ }^{33}$. La expresión "estrategia" comunica la idea de una planificación, y la expresión "discursiva" la hemos preferido porque enfatiza que el acto de la entrevista y las palabras dichas intermedian entre los significados que se pretendían comunicar y las prácticas de los jueces. Las "estrategias discursivas" cumplen entonces dos propósitos: organizar la progresión temática fijando el punto de interés en lo que se dice y, al mismo tiempo, guiar el proceso interpretativo del entrevistador e implicarlo en la conversación.

Las "estrategias discursivas" no son solo huellas o indicios, sino que involucran al oyente y le reclaman un compromiso o implicación conversacional ${ }^{34}$. Este compromiso es previo a la conversación y, al mismo tiempo, es un resultado de ella porque exige que el oyente participe en la interacción colaborando con el hablante en la producción del discurso. El compromiso es entonces un estado cognitivo de los participantes en la conversación y una disposición para establecer una relación social a través de las palabras.

\footnotetext{
31 FAIRCLOUGH (1995), p. 8.

32 Gumperz (1977), p. 193.

33 Gumperz (1977), p. 194.

34 Gumperz (1977), p. 196.
} 


\subsection{Criterios de fragmentación de las respuestas}

La estructura flexible de la entrevista permite que quien responda exprese sus ideas con bastante libertad, incluso yendo más allá de la respuesta a la pregunta formulada. Por esta razón la fragmentación de las respuestas usó una versión simplificada del modelo de análisis crítico de Fairclough que se concentró en la progresión informativa de las respuestas ${ }^{35}$. Cada respuesta fue dividida en dos partes siguiendo un criterio exclusivamente temático: la parte de la respuesta que suministra la respuesta directa a la pregunta (ID) y la parte que entrega información adicional no solicitada explícitamente (IA). A su vez, esta segunda parte de la respuesta se subdividió en dos: información adicional complementaria (IAC) e información adicional periférica (IAP), según el nivel de cercanía que presentaba con la pregunta con la que se relacionaba (estrecha en el caso de la primera; distante en el caso de la segunda).

Con estas categorías de trabajo el análisis consistió en mapear las relaciones de significado que permitiesen delinear en primer lugar el flujo temático de cada respuesta en el marco de la entrevista y, en segundo lugar, la importancia de cada nodo de información de acuerdo a la textura de la respuesta expresada en las estrategias discursivas involucradas. Así se construyó un diagrama de información relevante como una figura de tres anillos concéntricos cuyo centro es la ID, luego la IAC y después la IAP. De este modo, lo que hemos llamado el imaginario de los jueces sobre el modelo de la SC es el resultado de la triangulación de los flujos informativos de las seis entrevistas, en el entendido de que ese flujo es la manifestación de una práctica discursiva desinstitucionalizada y que las "estrategias discursivas" usadas por los jueces en esa práctica comunican cómo ellos entienden la valoración de la prueba desde cuatro perspectivas complementarias: la ideacional o el proceso mental de valoración; la experiencial o el proceso biográfico consistente en participar en procesos judiciales; la interpersonal o el vínculo en las relaciones con otros (colegas, abogados y ciudadanos) y la perspectiva textual o el modo en que los jueces hablan sobre su trabajo ${ }^{36}$.

\subsection{Los conceptos y las vivencias}

Muchas de las preguntas contenidas en el instrumento se distanciaron deliberadamente del punto de vista biográfico para concentrarse en algunas categorías y conceptos que la dogmática procesal y la teoría de la prueba

\footnotetext{
35 En el nivel oracional este análisis habitualmente adopta la terminología de tema y rema. JIMÉNEZ (1986).

36 Para el lector especializado estas cuatro perspectivas son las metafunciones de Michael Halliday. HALLIDAY (1970).
} 
han abordado para teorizar sobre la valoración de la prueba. Esta decisión se fundó en la idea de que los entrevistados respondiesen a las preguntas usando sus conocimientos previos. Naturalmente, al decidir usar una entrevista semiestructurada cifrábamos expectativas en que la dinámica de la conversación permitiese a los jueces hablar de sus vivencias laborales.

Como forma de representar el efecto que se buscaba lograr con las intervenciones del entrevistador, puede tenerse en consideración, a modo de ejemplo, una de las preguntas (muy simples) del instrumento que fue aplicado y que refiere puntualmente a las máximas de la experiencia: "Por favor explique qué entiende por máximas de la experiencia". Ya que esta pregunta debía ser formulada cuando había ya transcurrido más de la mitad del tiempo de la entrevista, era previsible que no se requiriesen mayores guías respecto de la clase de respuestas esperadas. Sin perjuicio de ello, el entrevistador en caso de ser necesario podía dar algunas pistas de carácter conceptual, por ejemplo, "¿Cuáles son las principales características de las máximas de la experiencia?"; podía reorientar las respuestas hacia lo biográfico si en el espacio de lo conceptual había incomodidad: "Ejemplifique con casos de su propia experiencia como juez"; como también podía apuntar hacia problemas relacionados con su impacto normativo o de identificación: "¿Le parecen útiles y fiables las máximas de la experiencia como guía para las decisiones? ¿Por qué?", "¿De dónde extrae Ud. la existencia de máximas de la experiencia para aplicar en un caso?". Solo resuelta dicha aproximación se planteaba una pregunta de segundo nivel que se esperaba sirviera en forma más acabada a la identificación del imaginario de la SC: "¿Considera Ud. que las máximas de la experiencia son comunes a todo individuo o dependen fuertemente de lo que haya sido su experiencia personal o entorno cultural?".

\subsection{Selección de los participantes}

La muestra seleccionada no es representativa de la comunidad de jueces. Su reducido número pretende solo arribar al mínimo de individuos para "replicar o extender la teoría emergente" a otros sujetos que les sean semejantes ${ }^{37}$. El número de jueces entrevistados responde entonces a dos criterios: replicabilidad y extensión. La replicabilidad posibilita que los diferentes entrevistados corroboren y falseen las proposiciones teóricas y la extensión permite que los constructos que forman la teoría puedan ser perfilados y desarrollados hasta su saturación o redundancia a partir de la información generada por las entrevistas ${ }^{38}$.

37 EISENHARDT (1989), pp. 532-550.

38 Glaser y Strauss (1967); Lincoln y Guba (1985), p. 204. 
Los jueces entrevistados fueron seleccionados a través de un sistema de preguntas a un panel de nueve abogados litigantes y académicos vinculados al derecho penal ${ }^{39}$, laboral ${ }^{40}$ y de familia ${ }^{41}$. Los abogados informantes fueron seleccionados por el primero de los autores teniendo en consideración su trayectoria, tanto académica como dentro del gremio (por ejemplo consejero del Colegio de Abogados) y diversidad institucional. Las preguntas realizadas apuntaban a que se indicasen jueces a quienes se reconocía como especialmente competentes en el ejercicio de la tarea de valorar la prueba disponible en un juicio ${ }^{42}$. De esta manera, se buscaba identificar a jueces que desde el punto de vista de un grupo de abogados destacados hubieran demostrado la capacidad de resolver adecuadamente las dificultades propias de valorar la prueba ${ }^{43}$. El panel definió un conjunto de siete jueces que obtuvieron dos o más menciones ${ }^{44}$ (el total de jueces que tuvieron a lo menos una nominación fue de 36). El conjunto de jueces que participaron de la investigación se describe en el cuadro siguiente:

\begin{tabular}{|c|c|c|c|c|c|}
\hline Denominación & Nombramiento & $\begin{array}{c}\text { Rango } \\
\text { de edad }\end{array}$ & Género & $\begin{array}{c}\text { Experiencia en } \\
\text { el Poder Judicial } \\
\text { (años) }\end{array}$ & $\begin{array}{c}\text { Duración de la } \\
\text { entrevista }\end{array}$ \\
\hline Jueza 1 & $\begin{array}{c}\text { Tribunal Oral en } \\
\text { lo Penal }\end{array}$ & $41-50$ & Fem. & $5-10$ & 104 minutos \\
\hline
\end{tabular}

\footnotetext{
39 Se consultó a cinco abogados penalistas, habiendo contestado tres de ellos. Uno es el socio principal de un estudio de abogados especializados en derecho penal que ha asumido la defensa en varios casos importantes a nivel de opinión pública; otro es académico con grado de doctor que también ejerce la profesión en un estudio; y el tercero es abogado de un órgano público y que se ha desempeñado como consultor.

40 Se consultó a cuatro abogados laboralistas, habiéndose obtenido respuestas de tres de ellos. Uno de ellos es académico de dedicación exclusiva; los otros dos combinan la actividad académica con el ejercicio de la profesión en estudios de abogados. Todos ellos son autores de varias publicaciones.

41 Se consultó a seis abogados civilistas con experiencia en derecho de familia. Uno de ellos ejerce la profesión combinándolo con funciones académicas; los otros dos tienen dedicación exclusiva en funciones académicas.

${ }^{42}$ Las preguntas fueron realizadas a través de un correo electrónico enviado por separado a cada uno de ellos. Una vez que se les explicaba la naturaleza de la investigación que se realizaría se les solicitaba indicar "el nombre de tres jueces y de dos ministros de Corte de Apelaciones de Santiago o Valparaíso que, a su juicio, hayan demostrado un buen desempeño en asuntos de valoración de la prueba". A los participantes se les garantizó confidencialidad tanto de sus respuestas, como de su participación como informantes claves.

${ }^{43}$ No se aspiraba a identificar jueces que fueran representativos de la comunidad judicial, sino a quienes estuvieren en puestos de avanzada, para así ilustrar lo que serían las variables propias de un imaginario que legitimase las actuaciones de los jueces.

${ }^{44}$ De este conjunto solo uno no aceptó participar en la investigación, aduciendo una muy elevada carga de trabajo.
} 


\begin{tabular}{|c|c|c|c|c|c|}
\hline Denominación & Nombramiento & $\begin{array}{c}\text { Rango } \\
\text { de edad }\end{array}$ & Género & $\begin{array}{c}\text { Experiencia en } \\
\text { el Poder Judicial } \\
\text { (años) }\end{array}$ & $\begin{array}{c}\text { Duración de la } \\
\text { entrevista }\end{array}$ \\
\hline Juez 2 & $\begin{array}{c}\text { Tribunal Oral en } \\
\text { lo Penal }\end{array}$ & $31-40$ & Masc. & $5-10$ & 72 minutos \\
\hline Jueza 3 & $\begin{array}{c}\text { Tribunal de } \\
\text { Familia }\end{array}$ & $41-50$ & Fem. & $11-15$ & 92 minutos \\
\hline Jueza 4 & Tribunal Laboral & $31-40$ & Fem. & $11-15$ & 79 minutos \\
\hline Ministro 1 & $\begin{array}{c}\text { Corte de Apela- } \\
\text { ciones }\end{array}$ & $\begin{array}{c}\text { Más de } \\
61\end{array}$ & Masc. & Más de 30 & 128 minutos \\
\hline Ministro 2 & $\begin{array}{c}\text { Corte de Apela- } \\
\text { ciones }\end{array}$ & $\begin{array}{c}\text { Más de } \\
61\end{array}$ & Masc. & Más de 30 & 84 minutos \\
\hline
\end{tabular}

Los jueces entrevistados fueron contactados mediante correo electrónico. La participación fue voluntaria y las entrevistas se aplicaron en el lugar de trabajo de los entrevistados. Cada entrevista fue grabada en audio y se transcribió. Se omitió realizar un registro etnográfico de aspectos paralingüísticos, gestuales, proxémicos y de contexto por tratarse de un estudio exploratorio. El instrumento fue validado en dos entrevistas piloto antes de ser aplicado a los participantes.

Antes de iniciar la entrevista fueron abordados los aspectos básicos y previos a la aplicación del instrumento: la utilización de la información, las condiciones de participación, la confidencialidad de los datos, entre otros que explicaban el significado del documento de consentimiento informado que precede al desarrollo de la entrevista ${ }^{45}$. Luego se completó una ficha del entrevistado con datos personales como nombre, edad, género, años de ejercicio de la judicatura, entre otros.

La primera parte de la entrevista aborda asuntos relacionados con la formación y experiencia de los jueces participantes. Los temas sugeridos giraron en torno al pregrado, la Academia Judicial y el aprendizaje del ejercicio de la función judicial. Dos asuntos especialmente enfatizados al momento del diseño del instrumento tuvieron que ver con el papel reconocido a ciertos saberes especializados en problemas como medicina, ingeniería, bioquímica o contabilidad, como también las limitaciones institucionales para el ejercicio de la función judicial. La segunda parte se introduce en los temas centrales de la investigación y en la tercera la conversación se enfoca en el significado de los conceptos usados por el legislador al regular la SC.

${ }^{45}$ Solo una(o) de los participantes indicó que prefería el anonimato. 


\section{Resultados ${ }^{46}$}

Los resultados que se presentan a continuación dan cuenta de algunos de los planteamientos más relevantes expresados por los jueces en las entrevistas aplicadas. En la parte inicial, se reconstruyen algunas ideas generales acerca de lo que ellos consideran esperable de su labor de adjudicación, como también algunas de las restricciones que dificultan que aquélla sea realizada de manera óptima. En la segunda parte se presentan observaciones de los jueces que apuntan directamente a lo que consideran constitutivo de operar en conformidad a la SC.

\subsection{El contexto dentro del cual operan los jueces que deben valorar la prueba en conformidad a la SC}

Una cuestión controvertida en la comunidad jurídica es la posibilidad de los jueces de desafiar el condicionamiento que generan las propias creencias y el uso del derecho para solucionar los conflictos que se les presentan. Como se sabe, decidir el conflicto según lo dispuesto por el derecho vigente es una cualidad que se valora al describir la figura de un juez, lo cual muchas veces reconduce la discusión hacia la determinación de lo que es el derecho vigente. Por cierto, resolver conforme a derecho no obedece únicamente a elecciones tomadas por los jueces frente a las alternativas disponibles en el sistema normativo y en la cultura jurídica, sino que también a restricciones que presenta el sistema de administración de justicia. Esta clase de problemas importa que sea considerada en forma previa a la identificación del imaginario de la SC, pues da cuenta de un punto de partida que es compartido por los jueces.

\subsubsection{Sobre resolver conforme a derecho}

En las entrevistas había preguntas respecto de las características de los buenos jueces, lo que los llevó a manifestarse respecto a lo que significa resolver conforme a derecho. Un primer aspecto abordado apunta en la dirección de que los jueces creen que es posible y, para algunos, deseable 'divorciarse de sus propias convicciones' para hacer bien el trabajo judicial.

"Yo creo que un juez tiene que ser capaz de divorciarse de sus propias convicciones y en el ejercicio profesional, apegarse a la ley." (Jueza 1, Pregunta 8, ID).

46 Prevenimos al lector interesado en el uso de la metodología que hemos omitido buena parte de ella en la exposición de los resultados de la investigación. La razón de esta omisión está en nuestra decisión sobre el lector ideal (modelo) del texto: ya que hemos optado por dirigirnos a juristas, jueces y abogados, en lugar de a expertos en Ciencias Sociales o Humanas, suprimimos todos los tecnicismos que podrían desalentar la lectura del texto para este lector. 
"Cuando nosotros fallamos, validamos las normas de comportamiento que todos hemos dictado burocráticamente -se supone- a través del Parlamento[...] Cruzo con luz verde porque tengo la expectativa [...] de que el tipo de al lado respeta la luz roja y tengo la expectativa [...] de que si el tipo no respeta la luz roja va a tener un parte y una sanción." (Jueza 1, Pregunta 1, IAC).

Esta perspectiva, por cierto, está muy lejos de ser unánime, pues se reconocen situaciones en que los textos normativos podrían ser derrotados en aras del resguardo de otros valores. Asimismo, se da cuenta de algunas características de las formulaciones normativas (y de los hechos) que hacen ilusoria la idea de una aplicación mecánica del derecho. Así, el conocimiento del derecho se combina, en algunas entrevistas, con ciertas cualidades personales como el 'sentido de la justicia' y la 'imparcialidad' o bien, con la eficiencia en la tarea de distribuir cargas y/o beneficios.

"No es que yo reste valor a la ley, pero la ley está hecha por seres humanos y para seres humanos, para solucionar los problemas humanos. Por lo tanto, darle un valor extremo a lo que está escrito ahí puntualmente en el Código Civil, por decirte algo, es un poco complejo..." (Jueza 3, Pregunta 7, IAC).

"[Los buenos jueces/ministros se caracterizan porque:] primero, tienen conocimientos jurídicos sólidos; segundo, están exentos de formalismos y atacan al fondo del asunto. En general, no se quedan en formalismos o detalles formales, y tienen un gran afán, un gran deseo de solucionar el conflicto directamente, llegar al fondo del asunto sin dilación." (Jueza 4, Pregunta 8, ID).

"Son personas que se han planteado: ¿qué es el derecho?, ¿cuál es el sentido de la justicia? Y se nota. Hay un desarrollo detrás, una posición filosófica[...] Uno ve que es un buen juez, un juez virtuoso, porque se sitúa con ponderación o imparcialidad ante cualquiera de las pretensiones de las partes."(Jueza 4, Pregunta 8, ID).

"Entonces tú ves que lo que está determinando la decisión no es ni el hecho, no es ni la norma sino que el valor que te haga preferir un determinado sistema interpretativo para en él apoyarte al momento de justificar tu decisión." (Ministro 1, Pregunta 17, IAP).

Hay cierta tensión respecto de la necesidad de formación institucional en disciplinas no jurídicas. En general, los jueces no admiten que haya saberes que no estén capacitados de manejar por sí mismos o que necesiten de ciertos conocimientos (no-jurídicos) para resolver mejor cierto tipo de casos. En este sentido, es muy claro que la figura del buen juez requiere de la 'decisión conforme a derecho' y que cualquier otra consideración es solo un accesorio.

"¿Cuál es la esencia del juez? No es que el juez sea el tecnócrata de la ciencia, sino que pueda decidir conforme a derecho, lo que realmente sea razonable en ese momento, aun cuando los peritos -que son los expertos- estén en disidencia." (Jueza 4, Pregunta 9, IAC). 
La 'resolución conforme a derecho' como centro de la figura del buen juez, expresa además una concepción sobre el derecho. El derecho es visto como un saber distinto y desconectado (independiente) de las otras disciplinas científicas. Desde un punto de vista interno, quien sabe derecho -aunque no sepa medicina, economía, psicología o mecánica- podrá resolver acertadamente el conflicto que juzga. Es probable que este imaginario sobre el juez y el derecho actúe como un marco socio-cultural que dificulte a los jueces apreciar tensiones fuera del marco de lo eminentemente jurídico.

\subsubsection{Sobre restricciones que afectan a los jueces al momento de aplicar el derecho $^{47}$}

Aunque los jueces se asumen como conocedores del derecho, ellos cuestionan el proceso de formación que han recibido en el pregrado y en la Academia Judicial. El foco principal de la crítica es la escasa orientación a la resolución de resolver problemas que tienen estos procesos y la existencia de algún grado de desconexión entre los estudios universitarios y el desempeño profesional. Al mismo tiempo, los entrevistados valoran el aprendizaje que lograron mediante el ejercicio progresivo de la profesión de abogado primero y de la judicatura, después.

"La universidad no forma jueces. La universidad a la que yo iba, por lo menos, forma abogados o conocedores de la ley [...] de los procedimientos. De todas maneras, esta formación de jueces en la universidad es muy pequeña [...] Lo más que yo me acuerdo es que se veían extractos de fallos [...] pero no era más que eso." (Ministro 2, Pregunta 2, ID).

"[La importancia de que estemos sometidos a un regulación] en la escuela no lo pasan [...] Es una falencia para efectos del ejercicio de la actividad que estoy desarrollando. [... La universidad] en materia penal te da herramientas dogmáticas para poder acercarte a cualquier caso [...] Ciertamente lo que te permite es la generación del lenguaje posible para el desempeño de tu profesión y en particular de tu calidad de juez." (Jueza 1, Pregunta 2, IAC).

"Que si bien es cierto, hay un programa de formación de la Academia Judicial, que te pasan talleres en conocimiento, no existe una verdadera capacitación sistemática y evaluada en forma homogénea y con factores objetivos respecto de cómo tú tienes que argumentar tus fallos. Uno lo va haciendo a pulso [...] el control en Santiago es muy difuso [...] se anula el $4 \%$ de los fallos [...] Muchos, sino todos los jueces hemos aprendido a hacer fallos a pulso. "(Jueza 4, Pregunta 6, IAP).

"Yo alzaría la edad como requisito para ser juez. Porque si tú lo ves, en la gran mayoría de los países extranjeros, llegar a ser juez no es tan sencillo. No basta con haber

\footnotetext{
47 Un estudio pormenorizado de las restricciones que modelan el sistema de administración de justicia puede verse en POSNER (2011), pp. 31 y ss.
} 
estudiado Derecho, y luego haber ido a la Academia Judicial, y después postular a juez. Creo que la experiencia de vida es muy importante." (Jueza 3, Pregunta 8, IAC).

No es claro si las expectativas por un proceso institucionalizado de formación en la universidad y en la Academia Judicial, por una parte, y la valoración de la formación informal como un miembro novel del Poder Judicial, por la otra, están en tensión o son, en realidad, parte de un mismo imaginario sobre las dificultades que es necesario superar para convertirse en juez. Aunque no es el objetivo de la investigación, este punto nos parece relevante porque es un lugar común en la comunidad jurídica reclamar la formalización e institucionalización de los procesos de aprendizaje sin reflexionar sobre cómo es posible afianzar mejor el ethos institucional del Poder Judicial.

La expectativa social sobre el desempeño del juez es un tópico que solo surgió de forma marginal. Sin embargo, es una cuestión que parece preocupar a los jueces.

"Nos quejamos de que los jueces "no me resuelven todos los problemas que yo quisiera y a la velocidad que yo quisiera". Pero cada vez que tengo un problema preferimos ir al juez para que nos resuelva, porque es mejor que el juez me lo diga. Esa es la perspectiva, por qué, porque así yo no me hago cargo, si la decisión no me gustó le echo la culpa al juez y si la decisión me gustó, también, me afirmo en ella." (Jueza 3, Pregunta 4, IAP).

Los jueces perciben que las partes del juicio trabajan equilibrando la tensión entre la celeridad y el interés por obtener una decisión favorable. Es destacable que del contexto de las entrevistas surja cierto grado de aceptación con la imagen que los jueces proyectan en la sociedad. Los entrevistados saben que son observados y juzgados en esferas públicas con criterios diversos y que en esa yuxtaposición de evaluaciones siempre alguien quedará insatisfecho. En este sentido, los jueces perciben que el ejercicio de valoración de la prueba está resguardado de la crítica pública solo en la medida en que el resultado probatorio sea coincidente con lo que la comunidad sabe. La presión de la opinión pública es considerada como una condición inherente de la tarea que desempeñan. Probablemente por una opción de ética profesional sumamente internalizada en la comunidad de los jueces, no hay espacios para concebir a dicha presión como una eventual excusa ante un trabajo que no resulte del todo bien hecho.

"Un juez si no sabe aguantar la presión, mejor que se dedique a otra cosa, porque presión va haber siempre... Que el Ministro del Interior despotrique contra los jueces por la televisión en cadena nacional, es una cosa fuerte, por supuesto. $O$ el que, el abogado se presente con la viuda que está sentada atrás, de negro, toda Ilorosa, para reclamar una mejor indemnización... Por otra parte, el juez vive en una sociedad... Uno se imagina cuando lee los textos como si el juez fuese caído del limbo. O sea viene del limbo, cae a la tierra, hace un rato justicia y vuelve al limbo... El juez es un ser humano común y corriente, como todos, que se levanta 
en la mañana, que se estaba mirando al espejo y que se cortó al afeitarse..." (Ministro 2, Pregunta 6, IAC).

Respecto de la falta de tiempo para analizar los casos, es una circunstancia que es considerada relevante, pero no se acepta como una variable que justifique decisiones de baja calidad.

"Nuestro sistema obliga que terminada la prueba entras a deliberar de inmediato y a resolver casi en el acto [...] A veces pienso que casos complejos debieran dejarlos macerar un poco más [...], darle una vuelta, revisarlo con más detalle. Creo que eso me gustaría." (Juez 2, Pregunta 6, ID).

"Hay que irse adaptando [a la carga laboral]. Esto redunda de repente en la calidad de los fallos, cierto. No hay mucho tiempo para constatar una doctrina." (Ministro 2, Pregunta 6, ID).

Un aspecto que los jueces entienden que es preciso mejorar para que el sistema funcione mejor, es el desempeño de los abogados; ellos, en general, se muestran insatisfechos con los aportes que hacen para la solución del caso.

"Los abogados, no litigan bien, no orientan a los jueces. Generalmente es uno el que tiene que cuestionar los que ellos no cuestionan, tanto desde un punto de vista de la prueba [...] como de la dogmática penal." (Jueza 1, Pregunta 6, ID).

"Uno ve la carga que tienen los fiscales [...] vienen muy mal preparados [...] Están colapsados, al menos esa es mi impresión. Antes venían más redondos los juicios y estoy seguro que no es desidia. Yo conozco muchos fiscales y las personas se esfuerzan muchísimo, pasan muchas horas en la fiscalía." (Juez 2, Pregunta 6, ID).

"[De las principales dificultades para un óptimo desempeño como juez habría que destacar] el desempeño deficiente de los abogados. En algunos casos complica la tarea, quizás la poca bibliografía que hay en la sede laboral." (Jueza 4, Pregunta 6, ID).

Aun cuando no considera que sea una condicionante para no desempeñarse de manera óptima, uno de los entrevistados indica:

"Los abogados cumplen su función [...] Claro el ideal es que el tipo lo haga lo mejor posible y para mi gusto lo mejor posible, entre otros requisitos, consiste en que tenga pleno conocimiento de la causa. Es bastante común en que se contrata un abogado para la segunda instancia que es donde estoy yo [...] Sabe muy bien lo que tiene que decir, pero si uno lo saca un poco de ese esquema que tiene preparado [...] no tiene idea [...] Sabe su recurso pero no sabe la causa y eso se nota pero a la legua." (Ministro 2, Pregunta 6, IAR).

Por cierto, existe también autocrítica respecto de la manera en que se hacen las cosas, siendo un ejemplo la atención que es prestada a las alegaciones de las partes:

"Hay un relator que te cuenta el asunto y si tú estás cansado o estás desinteresado, o estás pensando en el partido de fútbol o lo que sea, no estás atento o te duermes 
o cabeceas. Entonces es ahí... nos falta una mayor calidad en la atención." (Ministro 1, Pregunta 6, IAP).

Los condicionamientos internos y externos del ejercicio de las funciones judiciales, por cierto, van mucho más allá de lo que fue abordado en las entrevistas. No se habló de los ascensos, del prestigio, de la valoración del tiempo libre, de las remuneraciones, etcétera. Sin perjuicio de ello, los resultados de los que se da cuenta resultan muy útiles para abordar a continuación, de una manera suficientemente contextualizada, el aspecto central de esta investigación, esto es la relación de los jueces con la SC.

\subsection{El papel de la SC en la fase de valoración de la prueba}

Se aprecia un cierto grado de convergencia entre las definiciones y los ejemplos que los jueces suministran cuando se les pregunta por el significado de la SC y de sus subcategorías (en términos legislativos) de principios de la lógica, máximas de la experiencia y conocimientos científicamente afianzados. La convergencia -aunque sea parcial-es destacable porque frente a la carencia de legislación precisa y de trabajos dogmáticos que escapen de ciertas ideas generales, la comunidad judicial ha logrado delimitar expresiones que de su simple lectura aparecen como peligrosamente abiertas.

A diferencia de lo que ocurre cuando se da cuenta de aquello que ordenan, permiten o prohíben las reglas sustantivas- en que los abogados tienden a comunicar inmediatamente un concepto- los jueces tienden a sentirse más cómodos formulando ejemplos o narrando experiencias biográficas. A continuación, una pequeña muestra de esta constante en la entrevista a propósito de la solicitud a los jueces de que realizaran precisiones conceptuales respecto de los conocimientos científicamente afianzados. En la tabla que se inserta aparece indicada la posición de la oración en que el entrevistado abandona por primera vez los intentos de usar un lenguaje conceptual e introduce un ejemplo (en algunos casos, autobiográfico):

\begin{tabular}{|l|c|c|c|c|c|}
\hline $\begin{array}{l}\text { Posición de la oración en que se menciona, por } \\
\text { primera vez, un ejemplo dentro de la respuesta } \\
\text { completa }\end{array}$ & $1^{\mathrm{a}}$ & $2^{\mathrm{a}}$ & $3^{\mathrm{a}}$ & $\ldots$ & $15^{\mathrm{a}}$ \\
\hline Número de jueces que están en esta situación & 1 & 3 & 1 & & 1 \\
\hline
\end{tabular}

Los jueces entienden claramente las diferencias que trae consigo la SC respecto de lo que significaba operar con el modelo de la prueba tasada. Asimismo, consideran que el cambio no debe entenderse como el abandono, sin más, a la subjetividad de los jueces.

"Lo otro eran sistemas legales de prueba legal tasada, que son más o menos mecánicos [...] Los jueces sólo constatan que hayan dos testigos contestes: no si 
es verdad o no. Eso nos cambió cuando entramos a los sistemas de sana crítica. Tenemos más libertades pero también tiene más control, un control más estricto." (Juez 2, Pregunta 1, IAP).

"El juez no puede fallar a su antojo. Es decir, estas lógicas, el conocimiento científicamente afianzado y las máximas de la experiencia son una limitación inmensa al juez. El juez no puede fallar conforme a su criterio." (Jueza 1, Pregunta 19, ID).

Se advierten, eso sí, dificultades al momento de dar cuenta de qué es la SC, lo cual se refleja en eludir la locución SC, o bien en la formulación de discursos extensos que revelan una larga búsqueda de lo que con ella se ha querido decir.

"Al principio nosotros teníamos muchas confusiones de lo que era el significado de sana crítica. Estábamos muy convencidos de que era de íntima convicción y la verdad que es muy distinto hablar del sistema de la sana crítica al sistema de la íntima convicción. Pero lo hemos ido aprendiendo con el tiempo." (Juez 2). Más adelante da cuenta de un episodio ocurrido después de varios años de desempeñarse como juez -y con ocasión de haber sido invitado a dar un curso en que debía tratar la valoración de la prueba conforme a la SC- indicando que: "Cuando estaba preparándome yo dije esto no puede... Yo no voy a llegar a explicar esto. Me parece que esto es fatuo, esto no está bien y empecé a buscar información [...]" (Juez 2, Pregunta 3, IAC).

“¿Cómo yo juez adquiero la convicción? [...] Ahí tendrías que pedirle a una bola mágica, y el juez no tiene una bola mágica, el juez actúa conforme a la sana crítica [...] La valoración [conforme a] la sana crítica, está asociada a esto de que tú tienes una premisa sobre un tema, haces una deducción, de lo general a lo particular, y eso te da una conclusión que es lógica. Lo que te decía antes, si llueve todo se moja, que podría ser una máxima de la experiencia [...] Por ejemplo, en los casos generales de regímenes de visita, cuando una mamá no quiere que un papá vea a sus hijos; entonces, tú le dices: ¡A ver señora cual es la razón para que no se desarrolle un encuentro más o menos regular o permanente! No es que no quiero. Eso no es lógico [...]" (Jueza 3, Pregunta 14, ID).

"Te reitero: creo que hay mucha falta de conocimiento (de los jueces) en relación a la argumentación y, sobre todo, respecto al orden de la sana crítica. No se manejan o no se señalan no más y si se señalan, se señalan sin mucha sustancia." (Jueza 4, Pregunta 15, IAP).

"Se aprecia la prueba conforme a la sana critica: eso lo tenemos en todos los procedimientos .... Hoy puede un superior decir que el juez inferior violó la norma reguladora de la prueba, cuando al justificar su decisión incurre en atentados respecto de algunos de estos tres [conjuntos de reglas] lógica, experiencia y conocimientos científico y técnico [...] Hay que aceptar la manera como el juez apreció, porque es un ejercicio jurisdiccional de él, soberanamente. $Y$ yo puedo entrar a modificarlo, no para sustituirlo a él como juez, justamente, a pesar de que la relación me lo permite, sino que en la medida en que esa apreciación sea fruto de una inconsecuencia de la razón." (Ministro 1, Pregunta 16, IAC). 
El problema de los jueces al tratar de valorar la prueba conforme a la SC no es solo de carácter conceptual, sino que se vincula con que la clase de problemas a los que se ven enfrentados es demasiado diversa. Las particularidades no admiten ser capturadas por un número finito de directivas que están en condiciones de proveernos los principios de la lógica, las máximas de la experiencia y los conocimientos científicamente afianzados. Esto lleva a que los saberes que los jueces van amasando fruto de la observación, sean considerados como muy importantes.

"Bueno los fallos son difíciles. Los jueces tienen que ingeniárselas para poder calmar lo mejor posible la prueba y buscar de adónde sacar datos para ir construyendo las premisas básicas. O sea con el testimonio de éste puedo llegar a [...]" (Ministro 2, Pregunta 18, IAC).

"Por ejemplo este reconocimiento es malo, pero puedo tener otro reconocimiento bueno. Entonces todo va a depender de caso en caso. Su validez en sí misma y su validez con el resto de la prueba. Es como una especie de rompecabezas interno." (Jueza 1, Pregunta 10, ID).

"Hay como cierta destreza que uno adquiere de saber que, a veces, el trabajador es tremendamente lacónico en su declaración. Uno decía: Ah puede estar mintiendo, pero ya no. O sea te das cuenta que no, porque escuchas a los testigos y son igual de lacónicos. O sea tienen el mismo nivel cultural. Por lo tanto, tienen el mismo tipo de lenguaje, de gestos, no les gusta hablar en público, menos con micrófono. Pero eso uno ya lo sabe." (Jueza 4, Pregunta 6, IAP).

"Es imposible la plena objetividad [...] porque el conocimiento siempre pasa por este sujeto" (Ministro 1, Pregunta 16, IAP).

\subsubsection{Imaginario judicial y conocimientos científicamente afianzados}

Sobre los conocimientos científicamente afianzados afirman los jueces que se trata del conjunto de saberes propio de las ciencias (esto es menos trivial de lo que prima facie pareciera). Las diferencias se concentran en la extensión de la expresión, ya que algunos jueces resaltan que los conocimientos científicos son aquellos que provienen de las 'ciencias exactas', mientras que otros la utilizan, además, para aludir a los conocimientos de las ciencias sociales, humanas y también formales, como la matemática.

Así, por ejemplo, se sostiene que:

"[El conocimiento científicamente afianzado] pertenece a una adquisición cultural histórica, aquello que no es en la actualidad al momento en que se está juzgando y adoptando la decisión, susceptible de discusión en el plano del conocimiento científico, es decir, en el propio de las ciencias exactas." (Ministro 1, Pregunta $11, I D)$.

Una aproximación algo distinta se advierte cuando se dice que: 
"Los conocimientos científicamente afianzados son cualquiera que se refiera a los conocimiento científicos, desde la filosofía, o desde la ciencia, o desde la matemática." (Jueza 3, Pregunta 11, IT).

Es interesante tener en cuenta que esta última jueza también incluyó dentro de esta categoría, a las teorías asentadas de los juristas:

"[E]l saber jurídico, a mi gusto, es también un conocimiento científicamente afianzado, desde el punto de vista de una doctrina que está sumamente aprobada, acreditada, afianzada por la jurisprudencia, que no ha podido ser rebatida con argumentos tan poderosos como los que esa teoría presenta." (Jueza 3, Pregunta 11, ID).

Aparentemente, la clave para la diferenciación no provendría tanto de la posesión de determinadas cualidades de las teorías (¿verdad?) o de la naturaleza del objeto de estudio, sino más bien de la usabilidad y de la consolidación de los saberes dentro de una comunidad especializada. Esto último aparece reforzado por otro de los entrevistados:

"[El conocimiento científicamente afianzado es aquél] que la comunidad lo acepta como tal. Que la comunidad científica valga la redundancia acepta como tal." (Ministro 2, Pregunta 11, ID).

Pensamos que el éxito del que gozan las pruebas científicas basadas en la experimentación en el contexto de los procesos judiciales se debe a su reputación de objetivas y, en este sentido, a su confiabilidad para los legos en ciencia en términos de la reproducibilidad de los resultados obtenidos.

"Hay casos puntuales donde efectivamente los conocimiento científicos van a decidir un juicio, ¿ya? Entonces [...] les preguntamos a médicos... o sea ahí puedes recurrir a lectura especializada." (Jueza 3, Pregunta 11, IAC).

Dos tópicos estrechamente vinculados a los conocimientos científicos corresponden al rol de los expertos y peritos en los juicios y la distinción en ciencia y pseudociencia. Los jueces reconocen el papel de los peritos para la comprensión de asuntos revestidos de complejidad y que han sido estudiados en profundidad en el seno de ciertas disciplinas. Esto no obsta a que sientan que aprenden cada vez que resuelven un caso y que esos aprendizajes se convierten en un background de conocimientos que les permiten mejorar su desempeño en los procesos futuros (aun cuando están conscientes que no pueden competir con los expertos).

"Es muy peligroso que yo me trate de hacer el experto, porque nunca voy a tener la capacidad para superar lo que los expertos dicen. A lo más en términos periciales, yo soy de los que creen que los jueces podemos resolver ciertas dificultades de método, ciertas dificultades metodológicas." (Juez 2, Pregunta 5, IT).

"Yo no puedo ir contra el científico, cómo pongo el fallo, que si el método es correcto. Si la comunidad científica ha avalado que esto es así, ¿cómo voy y digo que le creo a éste y a este otro no? No tengo cómo." (Juez 2, Pregunta 11, IAC). 
"En la experiencia como juez, uno va aprendiendo [...] Ahí recién vas a tener un conocimiento. Quizás eso hace que haya un desnivel entre el juez que empieza y el que lleva más tiempo, desde ese punto de vista quizás podría ser deseable un piso básico elemental." (Jueza 4, Pregunta 9, IAC).

"Yo diría que sí les fundamental que un juez posea conocimientos técnicos y específicos] que tal vez las puede estudiar a propósito de un caso concreto... los conocimientos - digamos-científicos están a disposición en cualquier momento... Distinto es cuando tú vas a ejercer un cargo... en una judicatura especializada como es derecho de familia o penal, civil o laboral, o sea claro, ahí la idea es que tengas formación técnica que te ayude, digamos, a una especialidad." (Jueza 3, Pregunta 5, IT).

La distinción entre ciencia y pseudociencia ${ }^{48}$ es un problema que no resulta claro cómo debe enfrentarse, a pesar de la relevancia que se reconoce a la ciencia para la toma de decisiones.

"Yo creo que hay que considerar todo lo que sea conocimiento 'dentro del conocimiento'. Puede haber pseudociencias como dices tú. Habría que ver en el caso concreto cuánto peso va a tener esta pseudociencia." (Jueza 3, Pregunta 12, IAR).

"... vivimos en un mundo que está cambiando mucho. Están mis colegas resolviendo un tema sobre unos ritos chamánicos [...] y se presenta el imputado a decir yo soy chamán y trae otros médicos chamanes... Usted dice, yo sólo entiendo que esto es ciencia: lo convencional, lo que la racionalidad implica, lo que es conocimiento formal dentro de una universidad... Pero también uno tiene que tener, entender que el mundo ha ido cambiando... Me imagino que sería difícil para mí creerle a un tarotista..." (Juez 2, Pregunta 12, IAC).

Es importante reflexionar a futuro sobre algunos puntos respecto de los cuales ninguno de los entrevistados se refirió: la relación entre ciencia y tecnología, el impacto de la posibilidad de error en el resultado científico; el conflicto entre opiniones científicas divergentes, y la naturaleza evaluativa del peritaje y del informe pericial. Aunque no se incluyeron preguntas específicas y claras sobre ninguno de estos asuntos, los investigadores esperaban que los jueces hicieran referencia a ellos de alguna manera y esto no ocurrió.

\subsubsection{Imaginario judicial y máximas de la experiencia}

Los jueces entrevistados identifican las máximas de la experiencia con un saber socialmente construido que se expresa en comportamientos generalizados y recurrentes. Así, en el discurso de los jueces, las máximas de la experiencia se vinculan a las reglas sociales, a las costumbres sociales y a las experiencias colectivas, es decir, a aquellas vivencias que son comunes a todos (o la mayoría de) los miembros de la sociedad.

${ }^{48}$ Las entrevistas mostraron que la expresión "pseudociencia" no está suficientemente socializada, varios jueces pidieron aclaraciones acerca de su significado. 
"Entonces ahí tú estás viendo que el ser humano es: se identifica en la medida en que capta que otros son... Entonces, en la medida que los individuos vivimos una realidad de una misma manera, o sea que experimentamos vitalmente de manera cosas semejantes, idénticas, iguales, hay distintos grados[...] En fin, desde lo idéntico tú puedes alejarte un poco. Quiere decir que esto pasa a ser una experiencia común". (Ministro 1, Pregunta 13, IAC).

La vinculación que tiene la cultura en la configuración de las máximas de la experiencia se aprecia además en el reconocimiento de que son dependientes de una determinada época.

"[Era una máxima de la experiencia que la mujer] estaba más capacitada naturalmente que el hombre [para asumir el cuidado de los hijos]. Hoy día tú no puedes afirmar que eso sea una máxima de la experiencia, por la cantidad de objeciones que empiezan a surgir." (Ministro 1, Pregunta 13, IAC).

En la opinión de la mayoría de los jueces entrevistados es la vida social la que determina la configuración de las máximas de la experiencia y no al revés. De este modo las máximas de la experiencia no son descritas por los jueces como reglas arbitrarias, sino como guías de comportamiento que expresan el orden social imperante en la vida comunitaria. Aquí surgen dudas sobre la extensión de la expresión 'máxima de la experiencia', porque los jueces no se refieren a tópicos como los siguientes: la recursividad entre la vida social y la experiencia socio-cultural; el frame de aprendizaje que fija la vida social; la conflictividad entre las máximas de la experiencia; la relación entre máximas en una sociedad multicultural, entre otros.

\subsubsection{Imaginario judicial y principios de la lógica}

Los principios de la lógica según los entrevistados sirven para establecer límites al sinsentido o al absurdo. Esto es interesante ya que en vista de lo resuelto en algunas sentencias ${ }^{49}$ podríamos pensar que entre los jueces existe una visión de la lógica como altamente formalizada, que establece solo un límite muy primario a lo que es posible hacer al momento de valorar la prueba. A contrario, la lógica en la que están pensando -al menos algunos de los entrevistados- apuntaría a reglas acerca de lo que se puede hacer con el lenguaje.

"... cuando hablamos de límites de lógica, no estamos hablando de la lógica formal. Nadie me va a venir a decir: mire, lo que pasa es que usted no construyó bien el silogismo [...] Entonces, la lógica es el razonamiento dentro del contexto en que todos nos movemos, en que culturalmente nos movemos, sea más o menos aceptado, sin que sea considerado excesivamente prejuicioso." (Juez 2, Pregunta 14, IT).

${ }_{49}$ Corte de Apelaciones de Valparaíso, Rol No 539-2012, de 1 de junio de 2012. 
"Ya en el fondo lo que uno utiliza de un argumento lógico o la tesis es que el argumento o la tesis del demandado no resulten absurdos, no resulten poco razonables en ese sentido. Bueno lo que te decía anteriormente, el despido verbal: no resulta razonable que una persona de la noche a la mañana decida que no quiere ir a trabajar más y no diga nada y deje de venir. Eso sin ningún tipo de elemento anexo, sin ninguna motivación no parece muy razonable, no parece muy lógico ni nada, parece más bien absurdo." (Jueza 4, Pregunta 14, IAC).

"Entonces la lógica me permite llegar mucho más rápido a la conclusión de algo práctico, que no es necesariamente el conocimiento científico." (Jueza 3, Pregunta 14, IT).

Los jueces no trataron de las falacias, del error lógico y de las conjeturas. Su modo de pensar está orientado por la búsqueda de un punto fijo y confiable desde donde iniciar un proceso de argumentación que, desde su perspectiva, se va complejizando a medida que se integra información inestable y solo verosímil. En este sentido, el imaginario de los jueces no incluye la realización de experimentos mentales o de trayectos de pensamiento difuso, disgregado o sin un objetivo claro mientras se valora la prueba. Así, los jueces exponen una forma de trabajo intelectual rígida y un tanto mecanizada en donde el proceso de reflexión está siempre controlado por una meta: la decisión del caso. Esto, entre otras cosas, explica una cierta incomodidad cuando los saberes a los cuales los jueces necesitan recurrir se les presentan como más difusos.

"Tengo los conocimientos científicos que son estrictos desde algún punto de vista y que pueden ser aplicables a cualquier caso de estas equis características. Pero el caso se va complejizando a medida que yo tengo que ir visualizando más la aplicación de las máximas de la experiencia y de los límites de la lógica." (Jueza 3, Pregunta 15, IAC).

A pesar de ello existe la conciencia de que los jueces están fuertemente determinados por sus experiencias individuales, aun cuando no sean incluidas en las categorías ya señaladas.

"Alguien puede ir viajando en Transantiago y observar una señora que con mucha dificultad paga su pasaje y se sienta, pero también cómo mira, cómo actúa, cómo se sienta. Algo le mueve adentro y luego lo hace mirar la realidad de otra manera... Son experiencias tan tan particulares que no sé hasta dónde influyen." (Ministro 2, Pregunta 3, IAC).

\subsubsection{La competición entre los conocimientos científicamente afianzados, máximas de la experiencia y principios de la lógica}

La reproducción de hechos o fenómenos observables desde la perspectiva de los jueces parece ser garantía suficiente para tomar una decisión. En este sentido, las ciencias empíricas basadas en la repetición de experimentos que arriban a resultados similares y las máximas de la experiencia entendidas como 
prácticas sociales generalizadas y recurrentes son entendidas bajo un imaginario común: la reproductibilidad como base para la confianza:

"Las máximas de la experiencia te hablan de un saber que es un saber asociado a las prácticas de una determinada cultura, a la común ocurrencia, a los hechos asociados de repetición. El conocimiento científico es algo absolutamente probado, probado por la ciencia, que es lo que yo te decía antes." (Jueza 3, Pregunta 13, IAC).

"Yo los veo relacionados, yo creo que las máximas de la experiencia, para poder ser invocadas tienen que ser hipótesis corroboradas [...] Tiene que revestir la misma calidad que uno pudiera decirte conocimiento científicamente afianzado, que es una hipótesis corroborada por la experiencia." (Jueza 1, Pregunta 13 IAC).

"Mire, yo soy de los que trata de ocupar muy poco las máximas de las experiencias. Hoy en día habiendo tanto conocimiento científicamente afianzado, ya no requiero máximas de las experiencias. Estas fueron creadas por un profesor de derecho procesal que se llamaba Stein. En realidad, le faltaba la premisa mayor del argumento." (Juez 2, Pregunta 13, IT).

"Te vuelvo a insistir, yo creo que las máximas de la experiencia te ayudan con los conocimientos científicamente afianzados y con la lógica, pero no por sí solas." (Jueza 3, Pregunta 15, IAC).

\section{Discusión}

El análisis de los datos generados en las entrevistas relevó cuatro categorías de análisis: Contexto, Comprensión, Evaluación y Propuestas, todas ellas relacionadas con la valoración de la prueba conforme a la SC. Estas categorías engloban los principales aspectos que configuran el imaginario de los jueces y permiten reconocer patrones comunes de discurso de los entrevistados.

\subsection{Contexto y en especial de las restricciones que afectan a los jueces en lo que refiere a valorar la prueba conforme a la SC}

Los jueces comunican que valorar la prueba conforme a la SC es algo que han aprendido a realizar, principalmente, desde la experiencia adquirida en sus cargos. Los aprendizajes que se produjeron durante su paso por las universidades se relacionan fundamentalmente con saberes conceptuales propios de la disciplina jurídica -la función que llevan a cabo los jueces claramente no es considerada como uno de los focos a los cuales se dirigió el proceso formativo- y dentro de éstos se carece de una teorización asentada acerca de cómo se cumple con los requerimientos de valorar la prueba conforme a la $\mathrm{SC}^{50}$.

\footnotetext{
${ }^{50}$ Esto último no corresponde a una constatación que directamente se extraiga de los dichos de los jueces, sino que simplemente corresponde a la observación de que la valoración de la prueba conforme
} 
La existencia de la Academia Judicial no constituye un factor decisivo en orden a revertir el déficit formativo en las competencias judiciales, ni tampoco fortalecería su sentido de pertenencia a la comunidad de los jueces. Así, cualquiera sea la forma de selección de los postulantes, el plan de estudios o la calidad de los profesores de la Academia Judicial, 'lo que en realidad transforma a un abogado en un juez' es el desempeño cotidiano en cargos de inferior jerarquía dentro del Poder Judicial. Este es un juicio retrospectivo y limitado a las vivencias de los jueces entrevistados que estiman que la Academia Judicial no es una marca de identidad profesional. Se debe considerar, en todo caso, que no todos ellos participaron como estudiantes y que quienes lo hicieron, la experimentaron en una etapa temprana de su existencia (primeros cursos de formación).

Si bien hay aspectos relevantes del desempeño de la tarea judicial que los entrevistados asumen como condicionamientos respecto de los cuales no queda sino aceptar o resistir (por ejemplo, presión de la opinión pública), los hay otros en que se esperaría un cambio. Uno de los más vistosos corresponde al papel que desempeñan los abogados, el que con frecuencia se visualiza que no es todo lo útil que podría esperarse. El asunto es digno de ser considerado ya que con ello se podría estar comunicando que existe una forma de división del trabajo en el proceso judicial. Así, la debilidad de los aportes de algunas de las partes incide en que las sentencias sean de inferior calidad de la que podría esperarse, si todos los participantes en el juicio ejecutaran satisfactoriamente las tareas a su cargo. Esto permite anticipar una de las principales conclusiones que se extrae de la presente investigación en cuanto a lo que es el imaginario judicial de la SC y que refiere a que con ella se pretende cautelar una forma de racionalidad que podría llamarse objetiva, esto es que hay un compromiso con una forma de corrección intersubjetiva a la que los jueces que valoran la prueba están llamados a prestar un servicio importante.

En una medida menor -tal vez porque hay un reconocimiento de los avances alcanzados en la organización de la tarea judicial-se advierte que la carga de trabajo y el tiempo disponible para fallar los asuntos que ingresan al sistema judicial, constituyen factores que podrían dificultar que se resuelva de manera óptima. Esto nuevamente comunica el imaginario de que existe algo así como un modelo de sentencia $-y$ con ello de valoración de la prueba conforme a la SC- que es independiente de factores contextuales. Al menos para algunos de los jueces entrevistados se advierte que no se trata de fallar de la mejor manera posible habida cuenta de las restricciones que afectan al proceso de toma de decisión, sino de que hay maneras correctas de hacer las cosas, las que deben

a la SC es una clase de asunto que no se aborda -o bien que se plantea en términos extremadamente generales- en los textos preferentes de divulgación de los saberes jurídicos (manuales y tratados). 
cuidarse más allá de la optimización en el uso de recursos públicos a las que pudiera propender el legislador.

\subsection{Comprensión del modelo de la Sana Crítica}

Los jueces son proclives a describir el modelo de la SC desde su propia experiencia biográfica y no desde abstracciones. Esta individualización del discurso se infiere de cierta incomodidad para comunicar qué significa valorar la prueba según este modelo, más allá de la explicación mediada por los saberes expertos sobre la SC. Es esperable que la incomodidad provenga, por una parte, de la ausencia de un lenguaje dogmático que haga posible comunicar de manera estandarizada qué es lo que hace un juez cuando juzga un caso según el modelo en cuestión; y, por otra parte, de la imposibilidad de traducir la SC en una práctica judicial generalizada, estable y aceptada sobre la valoración de la prueba.

La tensión entre conceptos escurridizos y experiencias contradictorias generan incomodidad en los jueces al momento de responder preguntas conceptuales que, quizás, podrían ser respondidas de forma breve y concisa si existiese un discurso académico afianzado sobre estos problemas. La información que surge de las entrevistas muestra que los jueces no usan un lenguaje especializado para referirse a la SC y, ante las preguntas conceptuales, responden usando ejemplos y sus propias vivencias.

Los jueces comunican que el proceso de valoración de la prueba conforme a la SC supone absorber formas de procesar la prueba que son propias de otros contextos. La manera en que esto se realiza lleva a comprender la sentencia como una articulación coherente de los insumos que se encuentran disponibles, tanto en el juicio como fuera de éste. No tiene, entonces, demasiado sentido la búsqueda de la primacía de una forma de comprensión del mundo por sobre las restantes disponibles, más allá de la coherencia que sea posible alcanzar en el caso concreto según la opción que se ha tomado ${ }^{51}$. Esto se expresa, por ejemplo, en que no se advierte una preocupación especial por problemas tales como el error o la identificación de un cierto método estandarizado de producción del conocimiento, según sería propio de contextos fuertemente comprometidos con asuntos de naturaleza epistémica. En este mismo sentido, puede señalarse que tampoco se advierte entre los jueces incomodidad frente al problema de la demarcación entre lo que es conocimiento científico y el que no lo es, o en la manera en que pueden convivir pacíficamente reglas extraíbles desde la lógica, máximas de la experiencia o conocimientos científicamente afianzados desde las cuales se generen soluciones contradictorias para un caso concreto. Al parecer la solución tendrá que ser vista caso a caso, con lo cual

51 Bruner (2010), pp. 101-111. 
se comunica no solo que la sentencia constituye un hito que implica la toma de posición ante situaciones inciertas como son las planteadas en los procesos (falta de información, información contradictoria, inferencias inciertas, etc.), sino también que la tarea de los jueces no está del todo constreñida por lo que resulta posible desprender desde la lógica, desde las máximas de la experiencia y/o desde los conocimientos científicamente afianzados.

\subsection{Evaluación del modelo de la Sana Crítica}

Si el acto de juzgar es comprendido como un proceso de organización de un cúmulo de información actualmente disponible y cuyo valor está desconectado de su capacidad de representar el pasado, es comprensible que los jueces entrevistados evalúen el modelo de la SC como un proceso en donde prima la racionalidad objetiva, por sobre la subjetiva. Entenderemos como racionalidad objetiva aquélla que se compromete con una forma de predecibilidad de la decisión, en términos que se pueda entender como extraída desde una norma pre-existente. A su vez, entenderemos como racionalidad subjetiva a aquélla cuyo valor se hace depender de que el sujeto respete un pre-compromiso de hacer las cosas de cierta manera, independiente de los resultados a los que esto pueda llevar en un caso concreto.

Desde el imaginario judicial los datos suministrados por los medios de prueba son confiables en primer término, porque se refieren a fenómenos observables y repetibles y en segundo término, por su valor hermenéutico. La valoración de la prueba, en el imaginario de los jueces, es entonces un proceso computacional en donde la racionalidad objetiva es el criterio de toma de decisiones. Lo importante es arribar a un resultado consistente con los textos normativos más que reflejar qué ocurrió.

La primacía de la racionalidad objetiva es parte del ideario de la modernidad, porque tras la idea de privilegiar la definición de un conjunto de reglas por sobre la configuración de un conjunto de prácticas, es uno de los elementos centrales del imaginario social que configura la cultura política moderna ${ }^{52}$. En este sentido, el imaginario de los jueces sobre el proceso de valoración de la prueba es típicamente moderno: el proceso mental de valoración se construye como una secuencia ordenada de pasos que es transparente, mecánica e instrumental. El proceso es transparente porque permite fijar indubitadamente que algo ha ocurrido usando un conjunto de criterios que es siempre comprensible por un auditorio racional. El proceso es mecánico porque es esencialmente repetible y es susceptible de ser dividido en un conjunto más o menos preciso de pasos.

52 TAYLOR (2006), p. 44. 
Finalmente, el proceso es instrumental porque su valor solo se encuentra en sustentar la aplicación del derecho vigente a un caso concreto.

\subsection{Propuestas sobre el modelo de la Sana Crítica}

Los jueces imaginan que un mejor sistema de valoración de la prueba es aquél que fortalece la racionalidad objetiva. Ya que 'resolver conforme a derecho' es parte central de la autoimagen de juez, buena parte de la incomodidad que los entrevistados manifiestan con el funcionamiento del modelo de SC, podría ser reducida con medidas institucionales que convergen en el incremento de la racionalidad objetiva. Las principales medidas que pueden inferirse de las entrevistas de los jueces son cuatro: i) formar a los estudiantes de derecho en el modelo de valoración de la prueba en las universidades y fortalecerlo en la fase de formación especializada en la Academia Judicial; ii) asegurar un mejor aporte de los abogados en el proceso judicial; iii) rediseñar el proceso de formación de los jueces en el modelo de la SC y, iv) reglar de forma más explícita lo que es permitido y prohibido en el modelo de la SC.

Estos hallazgos confirman que la dinámica entre las teorías (la dogmática y la filosofía de la prueba), las prácticas judiciales y los imaginarios sobre esas teorías y prácticas nunca es unidireccional. El proceso social de dotar de significado a una acción es recursivo, porque la práctica matiza la teoría y, al mismo tiempo, contextualiza el imaginario. A su vez el imaginario sobre la práctica puede modificar la práctica misma y servir de base para modificar, con posterioridad, la teoría y así sucesivamente.

El proceso social que modificará el significado de la práctica judicial de valorar la prueba está todavía en curso, ya que las reformas legislativas que introdujeron el modelo de la SC en nuestro sistema jurídico solo cambiaron una parte de ese proceso social. Los imaginarios sociales sobre la figura del juez y sobre su trabajo, así como las prácticas judiciales más arraigadas en los jueces, no han sido completamente reformados, porque no es posible hacerlo por vía legislativa. Tampoco se ha renovado la teoría sobre el trabajo judicial. Por estas razones, comprender que el proceso social por el cual una práctica cambia de significado es siempre gradual, implica tener conciencia de que el ejercicio de reglar un procedimiento tomando prestado un modelo de valoración de la prueba desde otra cultura jurídica no elimina las diferencias existentes entre las experiencias jurídicas de los intervinientes y los ciudadanos, sino que solo las enmascara.

\section{Conclusiones}

El objetivo de las técnicas de investigación cualitativa no es predecir ni generalizar (en un sentido estadístico) a partir de un conjunto de datos dispo- 
nibles, sino comprender los fenómenos estudiados en el contexto en que ellos acontecen. En este sentido, las conclusiones que se desprenden de la presente investigación no deben ser interpretadas como enunciados universales (predicables sobre toda la comunidad de jueces), sino como enunciados transferibles a otros individuos que ejercen la judicatura en Chile, en la medida en que las condiciones de ejercicio de la profesión y de comprensión del fenómeno jurídico sean similares ${ }^{53}$. Así, las conclusiones son fragmentos del imaginario de los jueces sobre la SC y no una teoría acabada.

El discurso construido en las entrevistas muestra que los seis jueces que colaboraron con esta investigación tendieron a presentar un número acotado de razones retóricamente autosuficientes sobre cada uno de los tópicos abordados. En sus respuestas intentaron validar o naturalizar la práctica de valorar la prueba según el modelo de la SC, ante un entrevistador que se presentaba como un lego en materias jurídicas. Las estrategias discursivas y la progresión temática de las respuestas proporcionadas muestran un nivel importante de uniformidad. Tal uniformidad no es explicable como una casualidad, porque es altamente improbable que los jueces hayan improvisado respuestas ad-hoc convergentes. Todo indica que los entrevistados intentaron comunicar y reproducir un imaginario sobre la SC socialmente establecido en la comunidad judicial.

El imaginario judicial de los jueces sobre el modelo de la SC carece de un lenguaje abstracto estandarizado para dar cuenta de la auto-comprensión de lo que implica valorar la prueba conforme a ese modelo. Aquello no implica necesariamente la dispersión o inestabilidad de las prácticas judiciales, pero sí implica una imposibilidad comunicativa: la carencia de un lenguaje conceptual para hablar de un proceso mental -la valoración de la prueba- hace imposible que quienes despliegan ese proceso hablen de él 'desde afuera' o asumiendo un punto de vista no-biográfico. Esta imposibilidad no es trivial, porque el punto de vista no-biográfico permite formular un discurso con pretensiones de objetividad disociando el proceso del agente que lo ejecuta. Cuando solo contamos con experiencias biográficas y ejemplos para comunicar lo que se hace (o debe hacerse) para valorar la prueba conforme a la SC no podemos evaluar bien lo que los jueces han hecho en un caso determinado. Ese juicio siempre puede ser entendido como un asunto de competencia entre subjetividades (la del autor $\mathrm{v} / \mathrm{s}$ la del evaluador) o como un juicio que solapa un reproche personal al juez bajo una crítica a cómo se ejecutó el proceso de valoración de la prueba.

La diferenciación de lo que representa operar bajo un modelo de la SC respecto de lo que es propio de la prueba tasada no es un asunto problemático. En el segundo, los jueces constriñen su discrecionalidad por la vía de someterse a

53 Leonard y McAdam (2001), p. 185; Langley y Royer (2006), p. 80. 
reglas legisladas, lo que no ocurre en el primero. Sí se advierte como más compleja la diferenciación de la SC respecto de la íntima convicción, aun cuando se admita el papel que en la SC debe reconocerse a los principios de la lógica, máximas de la experiencia y conocimientos científicamente afianzados.

La función de los principios de la lógica, máximas de la experiencia y conocimientos científicamente afianzados -en cuanto proveen de inferencias que procesan la prueba disponible o bien formas de construcción de los discursos- no es equiparable a la que juegan las reglas del legislador. Así, a diferencia de la presión por conocer el derecho (en un sentido amplio) que los jueces entienden como ineludible, no se advierte que ellos se sientan constreñidos a comprender en términos autónomos, por ejemplo, la metodología de los peritos para construir inferencias. Esto conduce a que los jueces entiendan que la SC obliga fundamentalmente a valorar la prueba siguiendo un patrón de racionalidad objetiva, es decir, en términos de usar las reglas pre-constituidas para solucionar los casos.

Finalmente, la reconstrucción eminentemente biográfica de las prácticas judiciales no debe entenderse como una decisión de los jueces (o como el resultado de su desidia en la búsqueda de un lenguaje conceptual), sino más bien como un síntoma de un problema que, a nuestro juicio, padece la comunidad jurídica chilena. En Chile el escaso desarrollo de la dogmática y de la teoría del derecho impide que los jueces cuenten con herramientas discursivas para hablar de su trabajo desde un punto de vista no biográfico. Hay, entonces, una deuda pendiente que no es conveniente seguir aplazando: aquélla refiere a la necesidad de construir un discurso científico que permita a los operadores jurídicos dar cuenta de la clase de racionalidad que se despliega bajo el modelo de la SC.

\section{BiBLIOGRAFÍA CITADA}

BakHtIN, Mikhail (1981): "The dialogic imagination", en: M. Holquist (Ed.) The dialogic imagination: Four essays by Mikhail Bakhtin (Austin, University of Texas Press).

BenfeLD, Johann (2013): "Los orígenes del concepto de «sana crítica»", en: Revista de Estudios Histórico-Jurídicos (№ 35), pp. 569-585.

BRUNER, Jerome (2010): Realidad mental y mundos posibles. Los actos de la imaginación que dan sentido a la experiencia (Barcelona, GEDISA).

Calsamiglia, Helena y Tusón, Amparo (1999): Las cosas del decir. Manual de análisis del discurso (Barcelona, Ariel).

Carrizo, L., Espina, M., Klein, J.T. (2004): "Transdisciplinariedad y complejidad en el análisis social". Disponible en: <http://unesdoc.unesco.org/ images/0013/001363/136367s.pdf > [visitado el 20/12/2013]. 
CASTORIADIS, Cornelius (2007): La institución imaginaria de la sociedad (Buenos Aires, Tusquets).

Chettr, Sylvie (1996): "The case study method for research in small-and medium- sized firms", en: International Small Business Journal (Vol. 5, octoberdecember), pp. 73-85.

Coloma, Rodrigo (2012): “¿Realmente importa la sana crítica?", en: Revista Chilena de Derecho (Vol. 39, No 3), pp. 753-781.

Coloma, Rodrigo; Carbonell, Flavia; Alfaro, Christian; Avilés, Luis; Báez, Danilo; Bugueño, Claudia; Jorquera, Mariela; Olave, Mauricio; Rivera, Virginia; Soto, Cristian y Toledo, José (2009): "Nueve jueces entran en diálogo con nueve hipótesis acerca de la prueba de los hechos en el contexto penal", en: Ius et Praxis (Vol.16, № 2), pp. 3-56.

Coloma, Rodrigo; Pino, Mauricio y MonteCinOs, Carmen (2009): "Fundamentación de sentencias judiciales y atribución de calidad epistémica a las declaraciones de testigos en materia procesal penal", en: Revista de Derecho de la Pontificia Universidad Católica de Valparaíso (Vol. 33, № 2), pp. 303-344.

Cortés Luis y Camacho María Matilde (1998): ¿Qué es el análisis del discurso? (Barcelona, Octaedro y Ediciones Universitarias de Barcelona).

DACHLER, H. Peter (1997): "Does the distinction between qualitative and quantitative methods make sense", en: Organization Studies (Vol. 18, 4), pp. 709-724.

FairClough, Norman (1995): Critical Discourse Analysis: the Critical Study of Language (Londres, Longman).

GUMPERZ, J. (1977): "Sociocultural knowledge in conversational inference", en: 28th Annual round table monograph series on language and linguistics (Washington, Georgetown University Press), pp. 191-211.

HAACK, Susan (2001): "An epistemologist in the bramble-bush: at the Supreme Court with Mr. Joiner", en: Journal of Health Politics, Policy and Law (Vol. 26, № 2, april), pp. 217-245.

HallidaY, Mark (1970): "Language structure and language function", en: J. Lyons New horizons in linguistics (Harmondsworth, Penguin). Ver Campbell\&Wales, pp. 140-165.

HarrIS, Marvin (1976): "History and Significance of the Emic/Etic Distinction", en: Annual Review of Anthropology (Vol. 5), pp. 329-350.

HARRIS, Marvin (1980): "Chapter Two: The Epistemology of Cultural Materialism", en: Cultural Materialism: The Struggle for a Science of Culture (New York, Random House), pp. 29-45.

Headland, Thomas; Pike, Kenneth; Harris, Marvin (eds.) (1990): Emics and Etics: The Insider/Outsider Debate (Newbury Park, Sage Publications).

Huber, Peter (1993): Galileo's Revenge. Junk Science in the Courtroom. (New York, BasicBooks). 
JIMÉNEZ, Tomás (1986):"Aproximación al estudio de las funciones informativas", en: Cuadernos de Lingüística (España, Editorial Librería Ágora S.A.).

JODELET, Denisse (1986): "La representación social: Fenómenos, concepto y teoría", en: Moscovici, Serge, Psicología social II. Pensamiento y vida social. Psicología social y problemas sociales (Barcelona, Paidós), pp. 469-494.

Kitayama, Shinobu; Cohen, Dov (2007): Handbook of Cultural Psychology (New York, Guilford Press).

LASO, Jaime (2009): "Lógica y sana crítica", en: Revista Chilena de Derecho (Vol. $\left.36, N^{\circ} 1\right)$, pp. 143-164.

LANGley, Ann y Royer, Isabelle (2006): "Perspectives on Doing Case Study Research in Organizations", en: Management (9, 3), pp. 73-86.

LEONARD, Denis y McAdAm, Rodney (2001): "Grounded theory methodology and practitioner reflexivity in TQM research", en: International Journal of Quality \& Reliability Management (18), pp. 180-194.

MaxweLL, Joseph (1998): "Designing a Qualitative Study", en: L. Bickman D.J. y Rog (Eds.), Handbook of Applied Social Research Method (Thousand Oaks, CA, Sage), pp. 69-100.

Mej́́A, Julio (2004) "Sobre la investigación cualitativa. Nuevos conceptos y campos de desarrollo", en: Investigaciones sociales (Año VIII, № 13), pp. 277-299.

Nieva, Jordi (2010): La valoración de la prueba (Madrid-Barcelona-Buenos Aires, Marcial Pons).

Pérez, Josefa (2008): "Las prácticas discursivas institucionalizadas", en: Lingua Americana (XII, No 22), pp. 95-110.

PIKE, Kenneth Lee (ed.) (1967): Language in Relation to a Unified Theory of Structure of Human Behavior (Netherlands, Mouton).

POSNer, Richard (2011): Cómo deciden los jueces. (Madrid, Marcial Pons).

Ruız, José (1996): Metodología de la investigación cualitativa (Bilbao, Universidad de Deusto).

StOeker, Randy (1991): "Evaluating and Rethinking The Case Study", en: The Sociological Review (Vol 39, issue 1), pp. 88-112.

TARUfFo, Michele (2001): "Senso comune, esperienza e scienza nel ragionamento del giudice", en: Rivista trimestrale di Diritto e Procedura Civile (settembre), pp. 665-695.

TAYLOR, Charles (2006): Imaginarios sociales modernos (Buenos Aires, Paidós). VARelA, Francisco; Thompson, Evan y Rosch, Eleanor (2011): De cuerpo presente. Las ciencias cognitivas y la experiencia humana (Barcelona, Gedisa).

YIN, Robert (1989): Case Study Research: Design and Methods. Applied social research Methods Series (Newbury Park CA, Sage). 


\section{JURISPRUDENCIA CITADA}

Ministerio Público con Mans (2012): Corte de Apelaciones de Valparaíso, 1 de junio de 2012 (Recurso de Nulidad), Rol No 539-2012.

\section{ANEXO}

NÓMINA DE LAS PREGUNTAS QUE SE RELACIONAN CON LAS RESPUESTAS SELECCIONADAS

1. ¿Cuáles aspectos (conocimientos, destrezas, valores) de la formación que recibió en la carrera de derecho, le han resultado especialmente útiles para su desempeño como juez?

2. ¿Cuáles aspectos de la formación que recibió en la carrera de derecho considera que fueron insuficientes para su desempeño como juez?

3. ¿Ha habido otras instancias informales de construcción de conocimientos, desarrollo de destrezas o de valores que le hayan sido especialmente útiles para su desempeño como juez/ministro de corte de apelaciones?

4. A medida que ha aumentado su experiencia en tribunales, iha cambiado su forma para tomar decisiones o de motivar sus sentencias?

5. ¿Es fundamental que un juez posea conocimientos técnicos o específicos respecto a una materia que debe juzgar (por ejemplo cuando estos son delitos económicos o sexuales)?

6. ¿Cuáles son las mayores dificultades o limitaciones institucionales o contextuales a que se enfrenta en su trabajo como juez? ¿En qué medida conspiran éstas en contra de la dictación de sentencias óptimas? (ejemplo: carga laboral, bibliografía a la que puede acceder, tiempo máximo de dictación de sentencias, presión pública, dificultad en la comprensión del lenguaje de los testigos, desempeño deficiente de los abogados en los juicios, otras.)

7. ¿Cuáles aspectos (conocimientos, destrezas, valores) de la formación que recibió en la carrera de derecho, le han resultado especialmente útiles para su desempeño como juez?

8. ¿Cuáles son las cinco características más relevantes de un buen juez? ¿Qué caracteriza a un mal juez?

9. ¿Es fundamental que un juez posea conocimientos técnicos o específicos respecto a una materia que debe juzgar (por ejemplo contabilidad o medicina)?

10. ¿Cuáles de las pruebas que se presentan en un juicio son las que Ud. considera que están dotadas de mayor fuerza probatoria?

11. Por favor explique qué entiende usted por Conocimiento Científicamente Afianzado / Ejemplifique, si es posible, con casos de su propia experiencia como juez lo que son los conocimientos científicamente afianzados. 
12. ¿Qué marca para usted el límite entre lo que puede ser considerado ciencia y lo que sólo sería pseudociencia?

13. Por favor, explique qué entiende usted por Máximas de la Experiencia

14. Por favor explique qué entiende usted por Límites de la lógica / ¿Cuáles son las principales características de los principios de la lógica?

15. En el caso hipotético de que hubiere contradicciones entre conocimientos científicamente afianzados, máximas de la experiencia y límites de la lógica: ¿cuál debiera prevalecer y por qué?

16. ¿Considera Ud. que al confirmar o revocar fallos que han sido recurridos por problemas de apreciación de la prueba está dando una señal acerca de cómo los jueces de instancia debieran hacer las cosas, o bien solo es relevante para el caso concreto?

17. ¿Qué circunstancias lo llevan a no adherirse a la mayoría y dictar un voto disidente (de minoría)?

18. En términos generales, ¿considera Ud. que los jueces sometidos a sistemas de valoración de la prueba conforme a la sana crítica redactan sentencias satisfactorias en lo que refiere a dar (o no) por probados ciertos hechos relevantes de los casos que conocen?

19. En su experiencia, ¿considera Ud. que la exigencia legal de no ir en contra de conocimientos científicamente afianzados, máximas de la experiencia y límites de la lógica influye en que la decisión o motivación de sentencias concretas, sea diferente a la que habría planteado si sólo hubiera tenido que ceñirse a su íntima convicción? 